NBER WORKING PAPER SERIES

\title{
USING GOALS TO MOTIVATE COLLEGE STUDENTS: THEORY AND EVIDENCE FROM FIELD EXPERIMENTS
}

\author{
Damon Clark \\ David Gill \\ Victoria Prowse \\ Mark Rush \\ Working Paper 23638 \\ http://www.nber.org/papers/w23638 \\ NATIONAL BUREAU OF ECONOMIC RESEARCH \\ 1050 Massachusetts Avenue \\ Cambridge, MA 02138 \\ July 2017
}

Primary IRB approval was granted by Cornell University. We thank Cornell University and UC Irvine for funding this project. We thank Daniel Bonin, Linda Hou, Jessica Monnet, Mason Reasner, Peter Wagner, Laurel Wheeler and Janos Zsiros for excellent research assistance. Finally, we are grateful for the many helpful and insightful comments that we have received from seminar participants and in private conversations. The views expressed herein are those of the authors and do not necessarily reflect the views of the National Bureau of Economic Research.

NBER working papers are circulated for discussion and comment purposes. They have not been peer-reviewed or been subject to the review by the NBER Board of Directors that accompanies official NBER publications.

(C) 2017 by Damon Clark, David Gill, Victoria Prowse, and Mark Rush. All rights reserved. Short sections of text, not to exceed two paragraphs, may be quoted without explicit permission provided that full credit, including (C) notice, is given to the source. 
Using Goals to Motivate College Students: Theory and Evidence from Field Experiments Damon Clark, David Gill, Victoria Prowse, and Mark Rush

NBER Working Paper No. 23638

July 2017

JEL No. C93,I23

\begin{abstract}
Will college students who set goals for themselves work harder and achieve better outcomes? In theory, setting goals can help present-biased students to mitigate their self-control problem. In practice, there is little credible evidence on the causal effects of goal setting for college students. We report the results of two field experiments that involved almost four thousand college students in total. One experiment asked treated students to set goals for performance in the course; the other asked treated students to set goals for a particular task (completing online practice exams). Task-based goals had large and robust positive effects on the level of task completion, and task-based goals also increased course performance. Further analysis indicates that the increase in task completion induced by setting task-based goals caused the increase in course performance. We also find that performance-based goals had positive but small effects on course performance. We use theory that builds on present bias and loss aversion to interpret our results. Since task-based goal setting is low-cost, scaleable and logistically simple, we conclude that our findings have important implications for educational practice and future research.
\end{abstract}

Damon Clark

Department of Economics

University of California, Irvine

Irvine, CA 92617

and NBER

clarkd1@uci.edu

David Gill

Purdue University

Rawls 4023

Krannert School of Management

403 W. State St.

West Lafayette, IN 47907

gill53@purdue.edu

\author{
Victoria Prowse \\ Purdue Univeristy \\ 2072 Rawls Halls \\ 402 W. State Street \\ West Lafayette, IN, 47907 \\ vprowse@purdue.edu \\ Mark Rush \\ University of Florida \\ Department of Economics \\ P.O. Box 117140 \\ Gainesville, FL 32611-7140 \\ mark.rush@cba.ufl.edu
}




\section{Introduction}

Researchers and policy-makers worry that college students exert too little effort, with consequences for their learning, their graduation prospects, and ultimately their labor market outcomes. With this in mind, attention has focused on policies and interventions that could increase student effort by introducing financial incentives, such as making student aid conditional on meeting GPA cutoffs and paying students for improved performance. However, these programs are typically expensive and often yield disappointing results. ${ }^{1}$

In this paper we aim to discover whether goal setting can motivate college students to work harder and achieve better outcomes. We focus on goal setting for three main reasons. First, in contrast to financial incentives, goal setting is low-cost, scaleable and logistically simple. Second, students might lack self-control. In other words, although students might set out to exert their preferred level of effort, when the time comes to attend class or study, they might lack the selfcontrol necessary to implement these plans. The educational psychology literature finds that self-control correlates positively with effort, which supports the idea that some students underinvest in effort because of low self-control (e.g., Duckworth and Seligman, 2005, and Duckworth et al., 2012). Third, the behavioral economics literature suggests that agents who lack selfcontrol can use commitment devices to self-regulate their behavior. ${ }^{2}$ Goal setting might act as an effective internal commitment device that allows students who lack self-control to increase their effort. ${ }^{3}$

We gather large-scale experimental evidence from the field to investigate the causal effects of goal setting among college students. We study goals that are set by students themselves, as opposed to goals set by another party (such as a counselor or professor), because self-set goals can be personalized to each student's degree of self-control. We study two types of goals: self-set

\footnotetext{
${ }^{1}$ Studies using randomized experiments and natural experiments to evaluate the effects of financial incentives on the performance of college students have been inconclusive: Henry et al. (2004), Cha and Patel (2010), ScottClayton (2011), De Paola et al. (2012) and Castleman (2014) report positive effects; while Cornwell et al. (2005), Angrist et al. (2009), Leuven et al. (2010), Patel and Rudd (2012) and Cohodes and Goodman (2014) do not find significant effects. Although there is little consensus on the reason behind the failure of many incentive programs, Dynarski (2008) notes that the incentives may be irrelevant for many students, and Angrist et al. (2014) report that one-third of the students in their study failed to fully understand a relatively simple grade-based incentive scheme. In other experiments on college students, academic support services have been combined with financial incentives. Results on the performance effects of these interventions are again mixed: Angrist et al. (2009) and Barrow et al. (2014) report strong effects; Angrist et al. (2014) find weak effects; and Miller et al. (2011) find no significant effects. Financial incentives are also controversial due to concerns that they might crowd out intrinsic incentives to study (see, e.g., Cameron and Pierce, 1994, and Gneezy et al., 2011). See Lavecchia et al. (2016) for a survey of financial incentives in higher education.

${ }^{2}$ These commitment devices include purchase-quantity rationing of vice goods (Wertenbroch, 1998), deadlines (Ariely and Wertenbroch, 2002), commitments to future savings (Thaler and Benartzi, 2004), long-term gym membership contracts (DellaVigna and Malmendier, 2006), restricted access savings accounts (Ashraf et al., 2006) and Internet blockers (Patterson, 2016), while Augenblick et al. (2015) show that experimental subjects in the laboratory who are more present biased in the domain of work effort are more likely to use a commitment device. See Bryan et al. (2010) for a survey.

${ }^{3} \mathrm{~A}$ small and recent literature in economics suggests that goal setting can influence behavior in other settings. Harding and Hsiaw (2014) find that goal setting can influence consumption: energy savings goals reduced energy consumption. Choi et al. (2016) find that goal setting can affect savings: goal-based cues increased savings into $401 \mathrm{k}$ accounts. Finally, goals can increase worker performance even in the absence of monetary incentives for achieving the goal: see Corgnet et al. $(2015,2016)$ for laboratory evidence (although Akın and Karagözoğlu, forthcoming, find no effect of goals), Goerg and Kube (2012) for field evidence and Goerg (2015) for a concise survey. Although not focused on education, several psychologists argue for the motivational benefits of goals more generally (see, e.g., Locke, 1968, Locke et al., 1981, Mento et al., 1987, Locke and Latham, 2002, and Latham and Pinder, 2005).
} 
goals that relate to performance in a course (performance-based goals) and self-set goals that relate to a particular study task (task-based goals). Our performance-based goals are the goalbased counterpart to performance-based financial incentives (see footnote 1). Our task-based goals are motivated by recent research by Allan and Fryer (2011) and Fryer (2011) that suggests that financial incentives for grade-school-aged children work well when they are tied to task completion (e.g., reading a book).

In considering both task-based goals and performance-based goals, our aim is not to test which is more effective. Instead, we aim to understand separately the impacts of two goalsetting technologies that could easily be incorporated into the college setting. To do this, we ran two separate experiments, each with its own within-cohort treatment-control comparison. By learning whether each intervention is effective in its own right, we can provide policy makers and educators who are considering introducing a particular form of goal-setting with valuable information about the likely impact of the intervention. ${ }^{4}$

We administered two field experiments with almost four thousand college students in total. The subjects were undergraduate students enrolled in an on-campus semester-long introductory course at a public university in the United States. The course was well established prior to our study and has been taught by the same professor for many years. The course is worth four credit hours, and a letter grade of a $\mathrm{C}$ or better in the course is required to graduate with a bachelor's degree in the associated subject.

In the task-based goals experiment, students were randomly assigned to a Treatment group that was asked to set goals for the number of online practice exams that they would complete in advance of each midterm exam and the final exam or to a Control group that was not. We find that task-based goals are effective. Asking students to set task-based goals for the number of practice exams to complete increased the number of practice exams that students completed. This positive effect of task-based goals on the level of task completion is large, statistically significant and robust.

As well as increasing task completion, task-based goals also increased course performance. The obvious explanation for this last result is that the increase in task completion induced by setting task-based goals caused the increase in performance. Independent evidence that the increase in task completion caused the increase in performance comes from an estimate of the performance returns to completing practice exams. We obtained this estimate from a fixed effects estimator that exploits within-student variation in performance and practice exam completion in the Control group (who were not asked to set goals). Together, our results suggest that if tasks are chosen appropriately then task-based goals can improve educational performance as well as induce greater task-specific investments.

Interestingly, we also find that task-based goals were more effective for male students than for female students, both in terms of the impact on the number of practice exams completed and on performance in the course. This finding is consistent with evidence from other educational environments that suggests that males have less self-control than females (e.g., Duckworth and Seligman, 2005, Buechel et al., 2014, and Duckworth et al., 2015) and with Duckworth et al.

\footnotetext{
${ }^{4}$ We powered our experiments to detect plausible treatment-control differences. Given our aim to understand separately the impacts of two goal-setting technologies, we did not power our study to be able to test directly for differences in effectiveness across experiments. Because we had little evidence ex ante to guide us regarding the size of such differences, calculating power ex ante was not realistic.
} 
(2015)'s conjecture that educational interventions aimed at improving self-control may be especially beneficial for males.

In the performance-based goals experiment, students were randomly assigned to a Treatment group that was asked to set goals for their performance in the course or to a Control group that was not. The performance measures for which goals were set included the overall course letter grade and scores on the midterm exams and final exam. We find that performance-based goals had positive but small and statistically insignificant effects on course performance.

We use theory to help guide the analysis and interpretation of our findings. In particular, for each type of goal (performance- and task-based), we write down a simple model of goal setting and then use this to generate possible hypotheses. Our models build on Koch and Nafziger (2011) and are inspired by two key concepts in behavioral economics: present bias and loss aversion. The models imply that present-biased students will, in the absence of goals, under-invest in effort. By acting as salient reference points, self-set goals can serve as internal commitment devices that enable students to increase effort.

Our model of performance-based goal setting suggests three key reasons why performancebased goals might not be very effective in the setting that we studied. First, performance is realized in the future, and so a present-biased student might not care much about the losses incurred when failing to meet goals. Second, if students are overconfident in the presence of uncertainty about the relationship between effort and performance, then goals might not induce (productive) effort. ${ }^{5}$ Third, for most students the effort-performance relationship is likely to be stochastic, which makes performance-based goals risky and therefore less effective.

Our model of task-based goal setting suggests that, in the presence of present bias and loss aversion, task-based goals can be highly effective. Two of the considerations that reduce the effectiveness of performance-based goals do not apply: students control perfectly the level of task completion and know straightaway the level of task completion that they achieve. Furthermore, to the extent that task-based goals direct students toward productive tasks, the effect of overconfidence is mitigated. One hypothesis for why task-based goal setting is more effective for males than females is that males are more present biased. This is consistent with the evidence cited above from educational environments that suggests that men suffer more from self-control problems.

The main contribution of this paper is to provide credible empirical evidence that taskbased goal setting can increase the effort and performance of college students. We also show that performance-based goals have positive but small and statistically insignificant effects on performance. Our study represents a substantial innovation on existing experimental evaluations of the effects of goal setting on the effort and performance of college students. In particular, while a handful of papers in psychology use experiments to study the effects of self-set goals among college students (Morgan, 1987; Latham and Brown, 2006; Morisano et al., 2010; Chase et al., 2013), these differ from our analysis in three important respects. First, they rely on much smaller samples. Second, they have not explored the impact of performance-based goals on performance or the impact of task-based goals on performance. ${ }^{6}$ Third, they have not studied the effect of

\footnotetext{
${ }^{5}$ Our overconfidence explanation implies that students have incorrect beliefs about the best way to increase their academic achievement. This is consistent with the explanation given by Allan and Fryer (2011) for why performance-based financial incentives appear ineffective.

${ }^{6}$ Morgan (1987) is the exception, but this small-scale study of task-based goal setting does not report a
} 
task-based goals on task completion and, therefore, have not investigated the mechanism behind any performance effects of task-based goal setting. ${ }^{7}$

Numerous studies in educational psychology report non-causal correlational evidence which suggests that performance-based goal setting has strong positive effects on performance (e.g., Zimmerman and Bandura, 1994, Schutz and Lanehart, 1994, Harackiewicz et al., 1997, Elliot and McGregor, 2001, Barron and Harackiewicz, 2003, Linnenbrink-Garcia et al., 2008 and Darnon et al., 2009). Another contribution of our paper is to cast doubt on this correlational evidence using our experimental finding that performance-based goals have small and statistically insignificant effects on performance. The obvious explanation for the discrepancy between previous correlational estimates and our experimental estimate is that the correlational estimates do not identify the relevant causal effect. We use our sample to explore this possibility. In line with previous correlational studies, in our experiment students who set ambitious performance-based goals performed better: conditional on student characteristics, the correlation in our sample between course performance (measured by total number of points scored out of one hundred) and the level of the goal is $0.203(p=0.000)$ for students who set performance-based goals. The difference between the strong positive correlation based on non-experimental variation in our sample and the small and statistically insignificant causal effects that we estimate suggests that correlational analysis gives a misleading impression of the effectiveness of performance-based goals. ${ }^{8}$

Our analysis breaks new ground in understanding the impacts of goal setting among college students. In particular, our experimental findings suggest that for these students, task-based goals could be an effective method of mitigating self-control problems. As we explain in detail in the Conclusion of this paper, our findings have important implications for educational practice and future research. Many colleges already offer a range of academic advising programs, including mentors, study centers and workshops. These programs often recommend goal setting, but only as one of several strategies that students might adopt to foster academic success. Our find-

statistical test of the relevant treatment-control comparison. In particular, Morgan (1987) ran an experiment using one-hundred and eighty college students split into two control groups and three treatment groups. One treatment group set themselves goals for study time, pages to read and topics to cover. The second treatment group self-monitored but did not set goals. The third treatment group did both. The study tracked performance but did not report task completion. Average performance of the treated subjects was higher than that of control subjects. As noted above however, the paper does not report a statistical test of the performance difference between subjects who set goals and subjects in the controls.

${ }^{7}$ Using a sample of seventy-seven college students, Schunk and Ertmer (1999) studied teacher-set instead of self-set goals: they directed students who were acquiring computer skills to think about outcomes (that the students had already been asked to achieve) as goals. Meanwhile, a literature in psychology uses small-scale experiments to look at the effects of teacher-set goals on the learning of grade-school-aged children (e.g., LaPorte and Nath, 1976, Schunk, 1983, Schunk, 1984, Schunk and Rice, 1991, Schunk and Swartz, 1993, Schunk, 1996, and Griffee and Templin, 1997). There are important differences between teacher-set goals for grade-school-aged children and self-set goals for college students: first, college students can use self-set goals to regulate optimally their own behavior given their private information about the extent of their self-control problem; and second, in the school environment children are closely monitored by teachers and parents, which gives extrinsic motivation to reach goals (for instance, children might worry about explicit and implicit penalties, monetary or otherwise, for failing to achieve the goal set for them). Using a sample of eighty-four fourth-grade children, Shih and Alexander (2000) explore experimentally the effects of self-set goals (in particular, they study the effects of self-set goals for the number of fractions to solve in class on the ability to solve fractions in a later test).

${ }^{8}$ For students who set task-based goals, the correlation between course performance (measured by total number of points scored out of one hundred) and the level of the goal is $0.391(p=0.000)$, which is in line with correlational findings from educational psychology (see, e.g., Elliot and McGregor, 2001, Church et al., 2001, and Hsieh et al., 2007). 
ings suggest that academic advising programs should give greater prominence to goal setting, and that students should be encouraged to set task-based goals for activities that are important for educational success. Our findings also suggest that courses should be designed to give students opportunities to set task-based goals. In courses with some online components (including fully online courses), it would be especially easy to incorporate task-based goal setting into the technology used to deliver course content; in traditional classroom settings, students might be encouraged to set task-based goals in consultation with instructors, who are well placed to select productive tasks. In conjunction with our experimental findings, these possibilities demonstrate that task-based goal setting is a scaleable and logistically simple intervention that could help to improve college outcomes at low cost. This is a promising insight, and we argue in the Conclusion that it ought to spur further research into the effects of task-based goal setting in other college contexts (e.g., two-year colleges) and for other tasks (e.g., attending lectures or contributing to online discussions).

The paper proceeds as follows. In Section 2 we describe our field experiments; in Section 3 we present the results of our task-based goals experiment; in Section 4 we present the results of our performance-based goals experiment; in Section 5 we interpret our results using theory that is inspired by present bias and loss aversion; and in Section 6 we conclude by discussing the implications of our findings. 


\section{Experimental design and descriptive statistics}

\subsection{Description of the sample}

We ran our field experiments at a public university in the United States. Our subjects were undergraduate students enrolled in a large on-campus semester-long introductory course. The course was well established prior to our study and has been taught by the same professor for many years. The course is worth four credit hours, and a letter grade of a $\mathrm{C}$ or better in the course is required to graduate with a bachelor's degree in the associated subject.

As described in Section 2.2, we sought consent from all our subjects (the consent rate was ninety-eight percent). Approximately four thousand students participated in total. We employed a between-subjects design: each student was randomized into the Treatment group or the Control group immediately on giving consent. Students in the Treatment group were asked to set goals while students in the Control group were not asked to set any goals. As described in Section 2.3, in the Fall 2013 and Spring 2014 semesters we studied the effects of performance-based goals on student performance in the course (the 'performance-based goals' experiment). As described in Section 2.4, in the Fall 2014 and Spring 2015 semesters we studied the effects of task-based goals on task completion and course performance (the 'task-based goals' experiment). ${ }^{9}$

Table 1 provides statistics about participant numbers and treatment rates. We have information about participant demographics from the university's Registrar data: Tables SWA.1, SWA.2 and SWA.3 in Supplementary Web Appendix I summarize the characteristics of our participants and provide evidence that our sample is balanced. ${ }^{10}$

\begin{tabular}{|c|c|c|c|}
\hline & All semesters & $\begin{array}{c}\text { Fall } 2013 \text { \& Spring } 2014 \\
\text { (Performance-based goals) }\end{array}$ & $\begin{array}{c}\text { Fall } 2014 \& \text { Spring } 2015 \\
\text { (Task-based goals) }\end{array}$ \\
\hline Number of participating students & 3,971 & 1,967 & 2,004 \\
\hline Number of students in Treatment group & 1,979 & 995 & 984 \\
\hline Number of students in Control group & 1,992 & 972 & 1,020 \\
\hline Fraction of students in Treatment group & 0.50 & 0.51 & 0.49 \\
\hline
\end{tabular}

Notes: The number of participating students excludes: students who did not give consent to participate; students who formally withdrew from the course; students who were under eighteen at the beginning of the semester; students for whom the university's Registrar data does not include SAT or equivalent aptitude test scores; and one student for whom the Registrar data does not include information on gender.

Table 1: Participant numbers and treatment rates.

\footnotetext{
${ }^{9}$ We also ran a small-scale pilot in the summer of 2013 to test our software.

${ }^{10}$ For each characteristic we test the null that the difference between the mean of the characteristic in the Treatment Group and the Control group is zero, and we then test the joint null that all of the differences equal zero. The joint test gives $p$-values of $0.636,0.153$ and 0.471 for, respectively, all semesters, Fall 2013 and Spring 2014 (the performance-based goals experiment), and Fall 2014 and Spring 2015 (the task-based goals experiment). See Tables SWA.1, SWA.2 and SWA.3 for further details.
} 


\subsection{Course structure}

In all semesters, a student's letter grade for the course was based on the student's total points score out of one hundred. The relationship between total points scored and letter grades was fixed throughout our experiments and is shown in the grade key at the bottom of Figure SWA.1 in Supplementary Web Appendix II. The grade key was provided to all students at the start of the course (via the course syllabus) and students were also reminded of the grade key each time they checked their personalized online gradecard (described below).

Points were available for performance in two midterm exams, a final exam and a number of online quizzes. Points were also available for taking an online syllabus quiz and a number of online surveys. For the Fall 2013 semester Figure 1 gives a timeline of the exams, quizzes and surveys, and the number of points available for each. As described in Sections 2.3 and 2.4, the course structure in other semesters was similar.

Each student had access to a private personalized online gradecard that tracked the student's performance through the course and that was available to view at all times. After every exam, quiz or survey, the students received an email telling them that their gradecard had been updated to include the credit that they had earned from that exam, quiz or survey. The gradecards also included links to answer keys for the online quizzes. Figure SWA.1 in Supplementary Web Appendix II shows an example gradecard for a student in the Control group in the Fall 2013 semester.

In all semesters, students had the opportunity to complete practice exams that included question-by-question feedback. The opportunity to take practice exams was emphasized on the first page of the course syllabus. ${ }^{11}$

We sought consent from all of our subjects using an online consent form. The consent form appeared immediately after students completed the online syllabus quiz and immediately before the online start-of-course survey. Figure SWA.2 in Supplementary Web Appendix II provides the text of the consent form.

\footnotetext{
${ }^{11}$ In the Fall 2013 and Spring 2014 semesters the students downloaded the practice exams from the course website. In the Fall 2014 and Spring 2015 semesters the students completed the practice exams online.
} 


\begin{tabular}{|l|l|}
\hline Syllabus quiz and start-of-course survey \\
\hline Syllabus quiz & 2 points for completion \\
\hline Consent form & FOR TREATED AND CONTROL STUDENTS \\
\hline Start-of-course survey & $\begin{array}{l}\text { TREATED STUDENTS SET GOAL FOR LETTER GRADE IN COURSE } \\
2 \text { points for completion }\end{array}$ \\
\hline Online quizzes \\
\hline $\begin{array}{l}\text { 10 online quizzes throughout the semester } \\
\text { Each scored from } 0 \text { to } 3 \text { points }\end{array}$ \\
\hline Midterm exam 1 \\
\hline Scored from 0 to 30 points \\
Only maximum of midterm $1 \& 2$ scores counts for letter grade \\
\hline Midterm exam $\mathbf{2}$ \\
\hline Scored from 0 to 30 points \\
Only maximum of midterm $1 \& 2$ scores counts for letter grade \\
\hline \hline Final exam \\
\hline Scored from 0 to 34 points \\
\hline End-of-course survey \\
\hline 2 points for completion \\
\hline
\end{tabular}

Figure 1: Fall 2013 semester timeline

\subsection{Performance-based goals experiment}

In the Fall 2013 and Spring 2014 semesters we studied the effects of performance-based goals on student performance in the course. In the Fall 2013 semester treated students were asked to set a goal for their letter grade in the course. As outlined in Figure 1, treated students were asked to set their goal during the start-of-course survey that all students were invited to take. ${ }^{12}$ In the Spring 2014 semester treated students were asked to set goals for their scores in the two midterm exams and the final exam. As outlined in Figure 2, the treated students were asked to set a goal for their score in a particular exam as part of a mid-course survey that all students were invited to take. ${ }^{13}$

Figures SWA.3 and SWA.4 in Supplementary Web Appendix II provide the text of the goalsetting questions. In each case, the treated students were told that their goal would be private and that: "each time you get your quiz, midterm and final scores back, your gradecard will remind you of your goal." Figures SWA.5 and SWA.6 illustrate how the goal reminders were communicated to the treated students on the online gradecards. The gradecards, described in Section 2.2, were a popular part of the course: the median number of times students viewed their gradecard during the Fall 2013 and Spring 2014 semesters was twenty-three. In Spring 2014, when the mid-course survey before a particular exam closed, the students received an email telling them that their online gradecard had been updated to include the credit that they had earned from completing that mid-course survey; opening the gradecard provided a pre-exam reminder of the treated student's goal for their score in the forthcoming exam.

\footnotetext{
${ }^{12}$ Treated students set their goal after the quiz on the syllabus. In every semester the syllabus gave the students information about the median student's letter grade in the previous semester.

${ }^{13}$ The students were invited to take the mid-course survey three days before the exam.
} 


\begin{tabular}{|l|l|}
\hline \multicolumn{2}{|l|}{ Syllabus quiz and start-of-course survey } \\
\hline Syllabus quiz & 1 point for completion \\
\hline Consent form & FOR TREATED AND CONTROL STUDENTS \\
\hline Start-of-course survey & 1 point for completion \\
\hline \hline Online quizzes \\
\hline 9 online quizzes throughout the semester \\
Each scored from 0 to 3 points \\
\hline Mid-course survey $\mathbf{1}$ \\
\hline TREATED STUDENTS SET GOAL FOR SCORE IN MIDTERM EXAM 1 \\
2 points for completion \\
\hline Midterm exam $\mathbf{1}$ \\
\hline Scored from 0 to 30 points \\
Only maximum of midterm 1 \& 2 scores counts for letter grade \\
\hline Mid-course survey $\mathbf{2}$ \\
\hline TREATED STUDENTS SET GOAL FOR SCORE IN MIDTERM EXAM 2 \\
2 points for completion \\
\hline \hline Midterm exam $\mathbf{2}$ \\
\hline Scored from 0 to 30 points \\
Only maximum of midterm 1 \& 2 scores counts for letter grade \\
\hline \hline Mid-course survey $\mathbf{3}$ \\
\hline TREATED STUDENTS SET GOAL FOR SCORE IN FINAL EXAM \\
2 points for completion \\
\hline \hline Final exam \\
\hline Scored from 0 to 34 points \\
\hline End-of-course survey \\
\hline 1 point for completion \\
\hline
\end{tabular}

Figure 2: Spring 2014 semester timeline

\subsection{Task-based goals experiment}

In the Fall 2014 and Spring 2015 semesters we studied the effects of task-based goals on task completion and course performance. Specifically, we studied the effects of goals about the number of practice exams to complete on: (i) the number of practice exams that students completed (which we call the 'level of task completion'); and (ii) the students' performance in the course. The experimental design was identical across the Fall 2014 and Spring 2015 semesters.

The course structure in the Fall 2014 and Spring 2015 semesters was the same as that outlined in Figure 2 for the Spring 2014 semester, except that before each of the two midterm exams and the final exam, instead of setting performance-based goals, the treated students were asked to set a goal for the number of practice exams to complete out of a maximum of five before that particular exam (recall from Section 2.2 that students had the opportunity to complete practice exams in all four semesters). The treated students were asked to set the goal as part of a midcourse survey that all students were invited to take. Both the treated and control students had the opportunity to complete up to five practice exams online before each exam. The opportunity to take the online practice exams was communicated to the treated and control students in the course syllabus, in the mid-course surveys (see Figure SWA.7 in Supplementary Web Appendix 
II) and in reminder emails before each exam (see Figure SWA.8). Figures SWA.9 and SWA.10 show the practice exam instructions and feedback screens. ${ }^{14}$

Figure SWA.7 in Supplementary Web Appendix II provides the text of the goal-setting question. The treated students were told that their goal would be private and that: "when you take the practice exams you will be reminded of your goal." Figures SWA.9 and SWA.10 illustrate how the goal reminders were communicated to the treated students when attempting the practice exams. The treated students also received a reminder of their goal in the reminder email about the practice exams that all students received (see Figure SWA.8). Reminders were not provided on gradecards.

\subsection{Descriptive statistics on goals}

Table 2 presents some descriptive statistics on the goals that the treated students set and the extent to which they achieved these. Looking at the first row of Panel I, we see that the vast majority of treated students chose to set at least one goal, irrespective of whether the goal was performance based or task based. Looking at the second row of Panel I, we see that on average students in the performance-based goals experiment set performance goals of ninety percent (as explained in the notes to Table 2, all performance goals have been converted to percentages of the maximal performance), while on average students in the task-based goals experiment set task goals of four out of five practice exams. The third row of Panel I tells us that these goals were generally a little ambitious: achievement lagged somewhat behind the goals that the students chose to set. Given that the goals were a little ambitious, many students failed to achieve their goals: the fourth row of Panel I shows that each performance-based goal was reached by about one-quarter of students while each task-based goal was reached by about one-half of students. ${ }^{15}$ Panels II and III show that the same patterns hold for both male and female students.

\footnotetext{
${ }^{14}$ The students were invited to take the mid-course survey five days before the relevant exam. Practice exam reminder emails were sent three days before the exam, at which time the practice exams became active. The practice exams closed when the exam started.

${ }^{15}$ Within the performance-based goals experiment, goals and goal achievement varied little according to whether the students set a goal for their letter grade in the course or set goals for their scores in the two midterm exams and the final exam.
} 


\begin{tabular}{|c|c|c|}
\hline \multicolumn{3}{|c|}{ Panel I: All students in the Treatment group } \\
\hline & Performance-based goals & Task-based goals \\
\hline Fraction who set at least one goal & 0.99 & 0.98 \\
\hline Mean goal & 89.50 & 4.05 \\
\hline Mean achievement & 78.40 & 3.14 \\
\hline Fraction of goals achieved & 0.24 & 0.53 \\
\hline \multicolumn{3}{|c|}{ Panel II: Male students in the Treatment group } \\
\hline & Performance-based goals & Task-based goals \\
\hline Fraction who set at least one goal & 0.99 & 0.97 \\
\hline Mean goal & 90.35 & 4.03 \\
\hline Mean achievement & 79.50 & 3.03 \\
\hline Fraction of goals achieved & 0.25 & 0.50 \\
\hline \multicolumn{3}{|c|}{ Panel III: Female students in the Treatment group } \\
\hline & Performance-based goals & Task-based goals \\
\hline Fraction who set at least one goal & 0.99 & 0.99 \\
\hline Mean goal & 88.68 & 4.07 \\
\hline Mean achievement & 77.34 & 3.23 \\
\hline Fraction of goals achieved & 0.24 & 0.55 \\
\hline
\end{tabular}

Notes: The fraction who set at least one goal is defined as the fraction of students in the Treatment group who set at least one goal during the semester. A student is considered to have set a goal for her letter grade in the course if she chose a goal better than an E (an E can be obtained with a total points score of zero). Other types of goal are numerical, and a student is considered to have set such a goal if she chose a goal strictly above zero. The mean goal, mean achievement and fraction of goals achieved are computed only for the students who set at least one goal. The mean goal is calculated by averaging over the goals set by each student (that is, one, two or three goals) and then averaging over students (goals for the letter grade in the course are converted to scores out of one hundred using the lower grade thresholds on the grade key, and goals for scores in the midterms and final exam are rescaled to scores out of one hundred). Mean achievement is calculated by averaging within students over the outcome that is the object of each set goal and then averaging over students (outcomes that correspond to performance-based goals are converted to scores out of one hundred as described previously for the performance-based goals themselves). The fraction of goals achieved is calculated by averaging within students over indicators for the student achieving each set goal and then averaging over students.

Table 2: Descriptive statistics on goals for students in the Treatment group 


\section{Results of the task-based goals experiment}

We now describe the results of our task-based goals experiment. In Section 3.1 we show that task-based goals successfully shifted task completion. In Section 3.2 we show that task-based goal setting also improved student performance in the course. Finally, in Section 3.3 we use independent quantitative evidence to argue that the increase in task completion elicited by task-based goal setting caused the improvement in student performance.

\subsection{Impact of task-based goals on task completion}

In this section we study the impact of task-based goals on the level of task completion, defined as the number of practice exams that the student completed during the course. Recall that all students in the task-based goals experiment had an opportunity to complete up to five practice exams online before each of two midterms and the final exam, giving a maximum of fifteen practice exams. As explained in Section 2, all students received question-by-question feedback while they completed a practice exam. To preview our results, we find that asking students to set task-based goals for the number of practice exams to complete successfully increased task completion. The positive effect of task-based goals on task completion is large, statistically significant and robust.

We start by looking at the effects of task-based goals on the pattern of task completion. Figure 3(a) shows the pattern of task completion for the students in the Control group, who were not asked to set goals. For example, Figure 3(a) shows that almost all students in the Control group completed at least one practice exam during the course while around fifteen percent of the students in the Control group completed all fifteen of the available practice exams. Figure 3(b) shows how task-based goal setting changed the pattern of task completion. In particular, Figure 3(b) shows that the task-based goals intervention had significant effects on the bottom and the middle of the distribution of the number of practice exams completed: for example, taskbased goals increased the probability that a student completed at least one practice exam by more than two percentage points $(p$-value $=0.020)$ and increased the probability that a student completed eight or more practice exams by more than six percentage points $(p$-value $=0.004)$. 


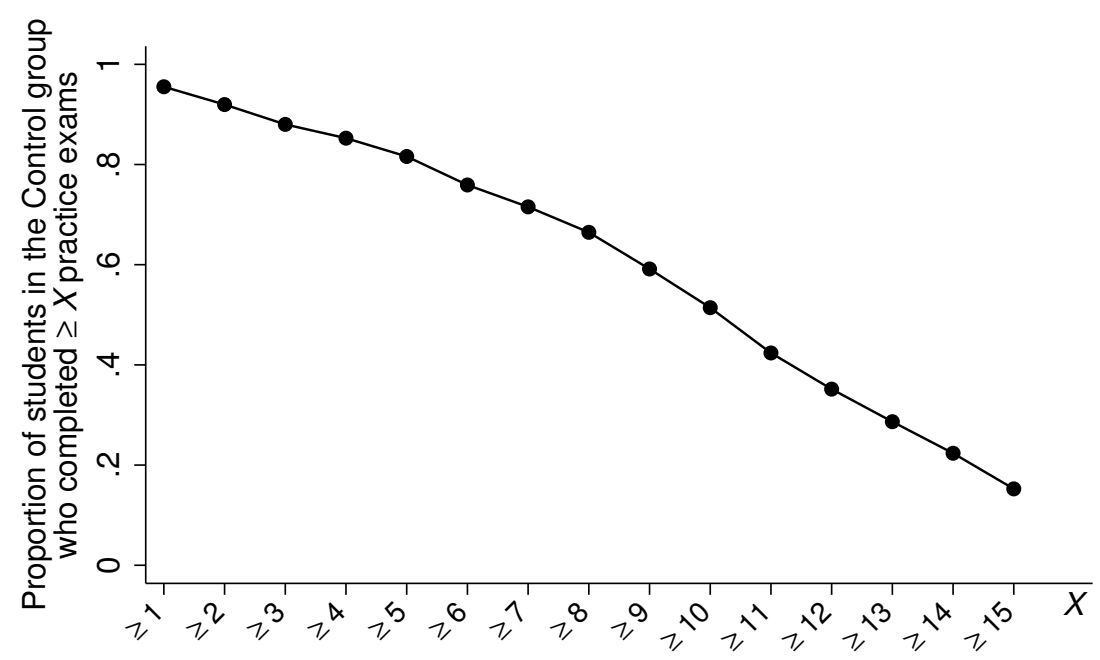

Number of practice exams completed

(a) Number of practice exams completed for students in the Control group of the task-based goals experiment

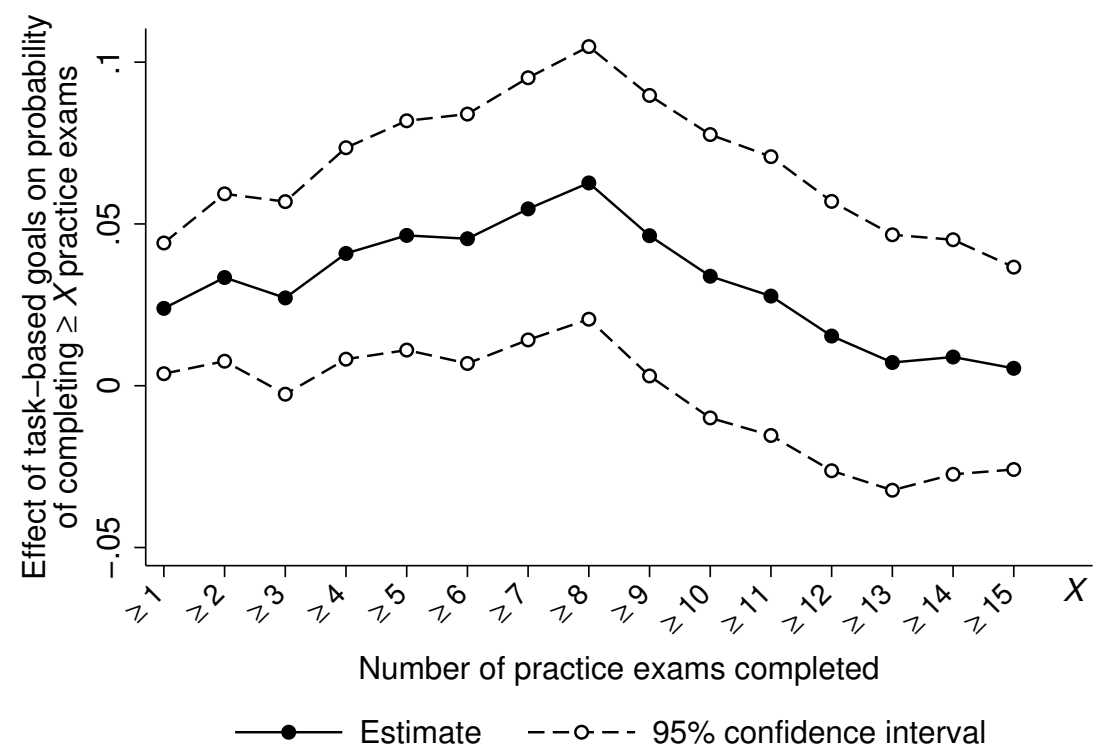

(b) Effects of task-based goals on the number of practice exams completed

Notes: The effects shown in Panel (b) were estimated using OLS regressions of indicators of the student having completed at least $X$ practice exams for $X \in\{1, . ., 15\}$ on an indicator for the student having been randomly allocated to the Treatment group in the task-based goals experiment. The $95 \%$ confidence intervals are based on heteroskedasticity-consistent standard errors.

Figure 3: Effects of task-based goals on the pattern of task completion 
Next, we look at how task-based goals changed the average level of task completion. Table 3 reports OLS regressions of the number of practice exams completed during the course on an indicator for the student having been randomly allocated to the Treatment group in the task-based goals experiment. To give a feel for the magnitude of the effects, the second row reports the effect size as a proportion of the standard deviation of the number of practice exams completed in the Control group in the task-based goals experiment, while the third row reports the average number of practice exams completed in the same Control group. From the results in the first column, which were obtained from an OLS regression that includes controls for student characteristics, we see that task-based goals increased the mean number of practice exams that students completed by about 0.5 of an exam (the effect has a $p$-value of 0.017 ). This corresponds to an increase in practice exam completion of about 0.1 of a standard deviation, or almost six percent relative to the average number of practice exams completed by students in the Control group. From the second column we see that these results are quantitatively similar when we omit the controls for student characteristics.

All students in the task-based goals experiment

\begin{tabular}{|c|c|c|}
\hline & \multicolumn{2}{|c|}{ Number of practice exams completed } \\
\hline & OLS & OLS \\
\hline \multirow[t]{3}{*}{ Effect of asking students to set task-based goals } & $0.491^{* *}$ & $0.479^{* *}$ \\
\hline & $(0.205)$ & $(0.208)$ \\
\hline & {$[0.017]$} & {$[0.022]$} \\
\hline Effect / (SD in Control group) & 0.102 & 0.100 \\
\hline Mean of dependent variable in Control group & 8.627 & 8.627 \\
\hline Controls for student characteristics & Yes & No \\
\hline Observations & 2,004 & 2,004 \\
\hline
\end{tabular}

Notes: Both columns report OLS regressions of the number of practice exams completed during the course (out of a maximum of fifteen) on an indicator for the student having been randomly allocated to the Treatment group in the task-based goals experiment. In the first column we control for student characteristics as described in the notes to Table 5 while in the second column we do not control for student characteristics. 'SD in Control group' refers to the standard deviation of the dependent variable in the Control group. Heteroskedasticity-consistent standard errors are shown in round brackets and two-sided $p$-values are shown in square brackets. ${ }^{*},{ }^{* *}$ and ${ }^{* * *}$ denote, respectively, significance at the $10 \%, 5 \%$ and $1 \%$ levels (two-sided tests).

Table 3: Effects of task-based goals on the average level of task completion

As we discussed in the Introduction, evidence from other educational environments suggests that males have less self-control than females. This motivates splitting our analysis by gender to examine whether self-set task-based goals act as a more effective commitment device for male students than for females. In line with this existing evidence on gender differences in self-control, Table 4 shows that the effect of task-based goals is mainly confined to male students. We focus our discussion on the first column of results, which were obtained from OLS regressions that include controls for student characteristics (the second column of results shows that our findings are robust to omitting these controls). Panel I shows that task-based goals increased the number of practice exams that male students completed by about one exam. This corresponds to an 
increase in practice exam completion of about 0.2 of a standard deviation, or almost eleven percent relative to the average number of practice exams completed by male students in the Control group. This positive effect of task-based goals on the level of task completion for male students is statistically significant at the one-percent level. Panel II shows that for female students task-based goals increased the number of practice exams completed by less than 0.2 of an exam, and this effect is far from being statistically significant.

Interestingly, in the Control group female students completed more practice exams than males, and our task-based goals intervention eliminated most of the gender gap in practice exam completion. Specifically, in the Control group females completed seventeen percent more practice exams than males, while in the Treatment group females completed only seven percent more practice exams than males.

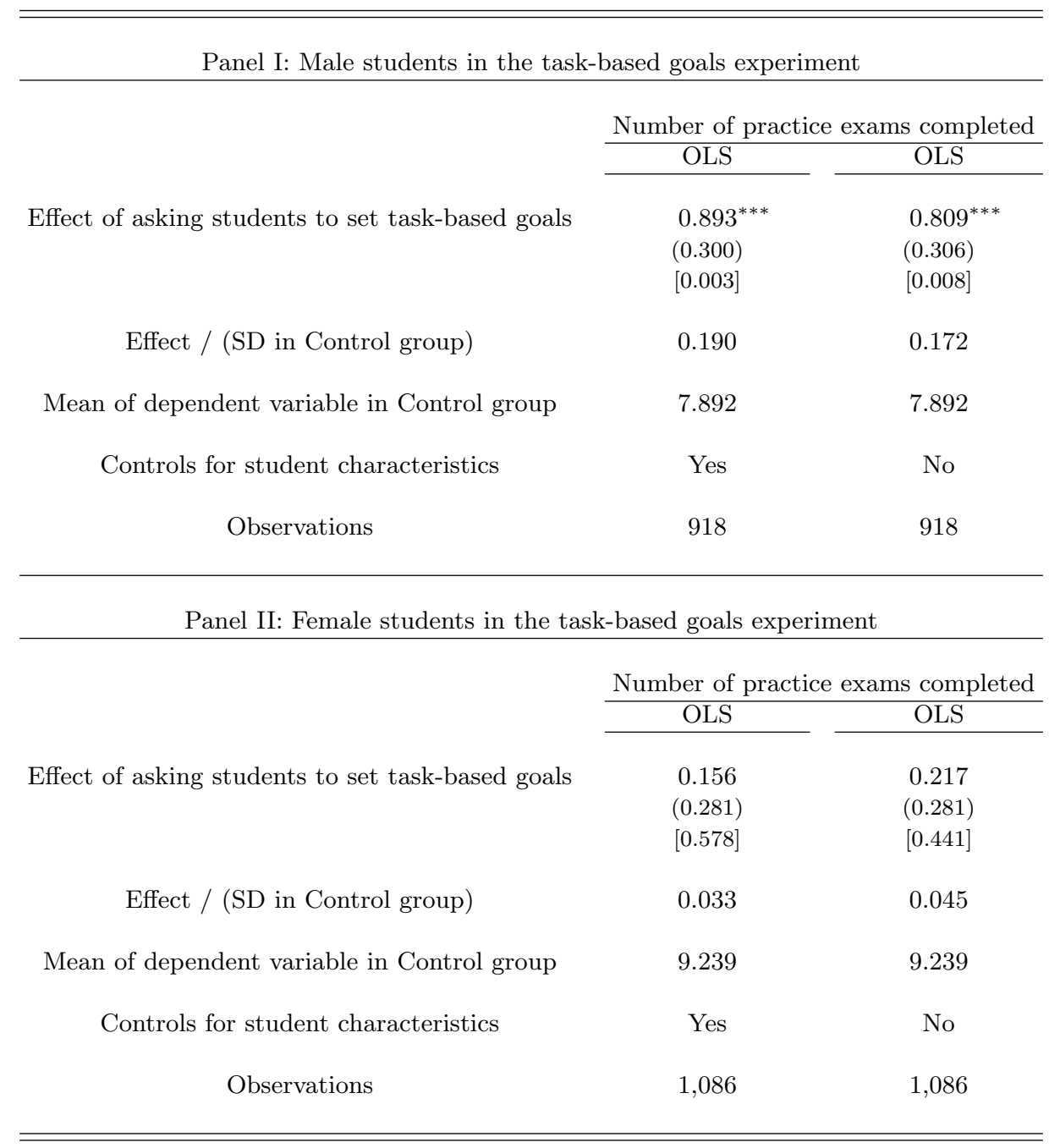

Notes: The regressions are the same as those reported in Table 3, except that we now split the sample by gender. Heteroskedasticity-consistent standard errors are shown in round brackets and two-sided $p$-values are shown in square brackets. ${ }^{*},{ }^{* *}$ and ${ }^{* * *}$ denote, respectively, significance at the $10 \%, 5 \%$ and $1 \%$ levels (two-sided tests).

Table 4: Gender differences in the effects of task-based goals on task completion 


\subsection{Impact of task-based goals on student performance}

We saw in Section 3.1 that task-based goal setting successfully increased the students' level of task completion. Table 5 provides evidence that asking students to set task-based goals also improved student performance in the course. We consider three measures of performance: (i) credit in the course, measured by students' total points score in the course (out of one hundred) that determines their letter grade; (ii) the probability that students achieved an A- or better; and (iii) the probability that students achieved a B+ or better. ${ }^{16}$ The first column of Table 5 reports OLS regressions of credit on an indicator for the student having been randomly allocated to the Treatment group in the task-based goals experiment. The second column, titled 'Median', reports unconditional quantile regressions for the median of credit on the same indicator. ${ }^{17}$ The third and fourth columns report OLS regressions of, respectively, an indicator for the student having achieved an $\mathrm{A}-$ or better and an indicator for the student having achieved a $\mathrm{B}+$ or better on the same indicator as in the first two columns. To give a feel for the magnitude of the effects, the second row in each panel reports the effect size as a proportion of the standard deviation of the dependent variable in the Control group in the task-based goals experiment, while the third row reports the average of the dependent variable in the same Control group.

Panel I of Table 5 shows that, across male and female students, asking students to set goals for the number of practice exams to complete improved performance by about 0.1 of a standard deviation on average across the four specifications. Two of the specifications give significance at the five-percent level, while the other two give significance at the ten-percent level. The tests are all two-sided: using one-sided tests would give significance at the one-percent level in two specifications and at the five-percent level in the other two.

Panels II and III show that task-based goals were effective for male students but not for females. For male students task-based goals improved performance by almost 0.2 of a standard deviation on average across the four specifications. This corresponds to an increase in credit of almost two points and an increase in the probability of achieving an A- or better of almost ten percentage points. The effects of task-based goal-setting on the performance of male students are strongly statistically significant (three of the four specifications give significance at the one-percent level, while the fourth gives significance at the five-percent level). On the other hand, Panel III shows that task-based goals were ineffective in raising performance for female students. On average across the four specifications, task-based goals improved the performance of female students by only 0.02 of a standard deviation (and the effect of task-based goals on the performance of female students is statistically insignificant in all four specifications).

The regressions in Table 5 control for student characteristics: the results are quantitatively similar but precision falls when we do not condition on student characteristics (see Table SWA.4 in Supplementary Web Appendix I).

\footnotetext{
${ }^{16} \mathrm{~B}+$ was the median letter grade across the four semesters of our study.

${ }^{17}$ The median results were obtained using the estimator of Firpo et al. (2009), which delivers the effect of the treatment on the unconditional median of credit.
} 
Panel I: All students in the task-based goals experiment

\begin{tabular}{|c|c|c|c|c|}
\hline & \multicolumn{2}{|c|}{ Total points score } & \multirow{2}{*}{$\frac{\operatorname{Pr}(\text { Grade } \geq A-)}{\text { OLS }}$} & \multirow{2}{*}{$\frac{\operatorname{Pr}(\text { Grade } \geq \mathrm{B}+)}{\text { OLS }}$} \\
\hline & OLS & Median & & \\
\hline \multirow{3}{*}{$\begin{array}{l}\text { Effect of asking students to set } \\
\text { task-based goals }\end{array}$} & $0.742^{*}$ & $1.044^{* *}$ & $0.038^{*}$ & $0.049^{* *}$ \\
\hline & $(0.431)$ & $(0.446)$ & $(0.021)$ & $(0.021)$ \\
\hline & {$[0.086]$} & {$[0.019]$} & {$[0.072]$} & {$[0.019]$} \\
\hline Effect / (SD in Control group) & 0.068 & 0.096 & 0.077 & 0.098 \\
\hline Mean of dependent variable in Control group & 83.111 & 83.111 & 0.393 & 0.493 \\
\hline Observations & 2,004 & 2,004 & 2,004 & 2,004 \\
\hline
\end{tabular}

Panel II: Male students in the task-based goals experiment

\begin{tabular}{|c|c|c|c|c|}
\hline & \multicolumn{2}{|c|}{ Total points score } & \multirow{2}{*}{$\frac{\operatorname{Pr}\left(\text { Grade } \geq \mathrm{A}^{-}\right)}{\text {OLS }}$} & \multirow{2}{*}{$\frac{\operatorname{Pr}(\text { Grade } \geq \mathrm{B}+)}{\text { OLS }}$} \\
\hline & OLS & Median & & \\
\hline Effect of asking students to set & $1.787^{* * *}$ & $1.714^{* * *}$ & $0.092^{* * *}$ & $0.069^{* *}$ \\
\hline task-based goals & $(0.657)$ & $(0.642)$ & $(0.031)$ & $(0.031)$ \\
\hline & {$[0.006]$} & {$[0.008]$} & {$[0.003]$} & {$[0.025]$} \\
\hline Effect / (SD in Control group) & 0.159 & 0.153 & 0.187 & 0.138 \\
\hline Mean of dependent variable in Control group & 83.285 & 83.285 & 0.417 & 0.529 \\
\hline Observations & 918 & 918 & 918 & 918 \\
\hline
\end{tabular}

Panel III: Female students in the task-based goals experiment

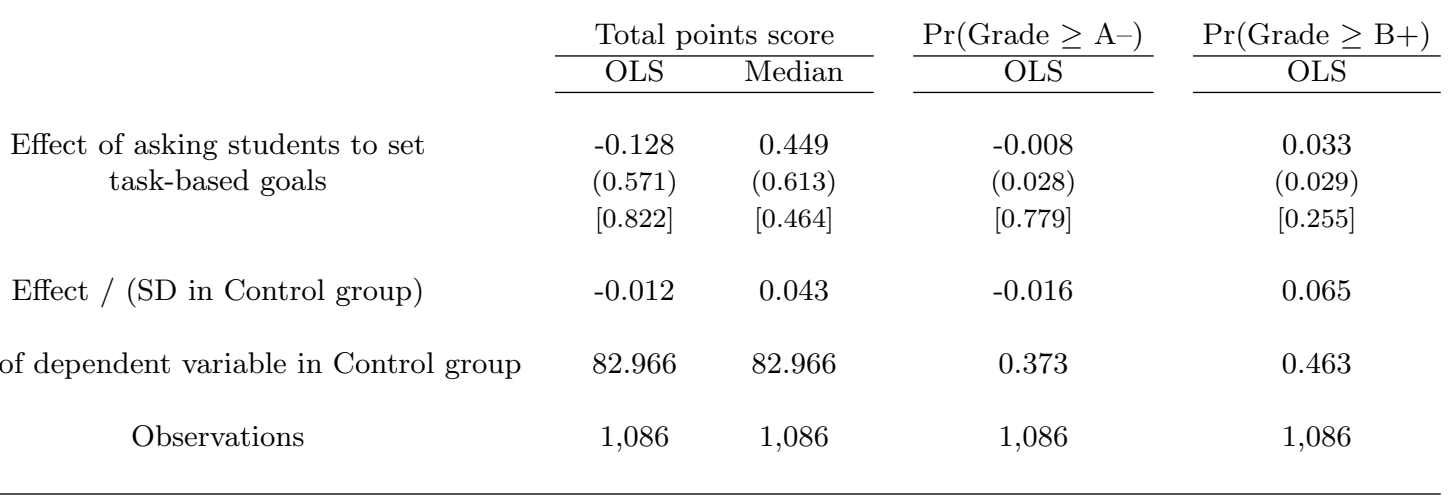

Notes: The first column reports OLS regressions of total points score on an indicator for the student having been randomly allocated to the Treatment group in the task-based goals experiment. The second column reports unconditional quantile regressions for the median of total points score on the same indicator. The third and fourth columns report OLS regressions of, respectively, an indicator for the student having achieved an A- or better and an indicator for the student having achieved a B+ or better on the same indicator as in the first two columns. 'SD in Control group' refers to the standard deviation of the dependent variable in the Control group. We control for the student characteristics defined in Table SWA.1 in Supplementary Web Appendix I: (i) letting $\mathcal{Q}$ denote the set containing indicators for the binary characteristics other than gender (race-based categories, advanced placement credit, Fall semester) and $\mathcal{Z}$ denote the set containing the non-binary characteristics (age, SAT score, high school GPA, first login time), we include $j \in \mathcal{Q}, k \in \mathcal{Z}, k \times l$ for $k \in \mathcal{Z}$ and $l \in \mathcal{Z}$, and $j \times k$ for $j \in \mathcal{Q}$ and $k \in \mathcal{Z}$; and (ii) the models in Panel I further include gender together with gender interacted with every control variable defined in (i). Heteroskedasticity-consistent standard errors are shown in round brackets and two-sided $p$-values are shown in square brackets. ${ }^{*},{ }^{* *}$ and ${ }^{* * *}$ denote, respectively, significance at the $10 \%$, $5 \%$ and $1 \%$ levels (two-sided tests).

Table 5: Effects of task-based goals on student performance 


\subsection{Did the increase in task completion cause the increase in performance?}

So far we have shown that task-based goals increased the level of task completion and improved student performance, with larger effects for male students than for females. A natural explanation for our results is that the increase in task completion induced by task-based goal setting caused the improvement in student performance. A final round of analysis provides independent evidence that supports this explanation. In particular, if the effect of goal setting on performance was caused by the increase in task completion, then this performance effect of goal setting should be comparable in magnitude to the effect of goal setting on the number of practice exams completed multiplied by the effect of completing a practice exam on performance. Evidence that this is the case comes from an estimate of the performance effect of completing a practice exam using a fixed effects estimation strategy. This strategy leverages within-student variation in the number of practice exams completed across the two midterms and the final exam among students in the Control group in the task-based goals experiment (who were not asked to set goals).

In more detail, we estimate the performance effect of completing a practice exam using a fixed effects regression of points scored in one of the midterms or the final exam (which enters the total points score as described in Section 2.4) on the number of practice exams completed in preparation for that midterm or final exam. Each student-exam pair is an observation and we include a fixed effect for each student. The estimation sample includes only students from the Control group of the task-based goals experiment. Thus the fixed effects estimate measures the performance returns to practice exams for students in the Control group who varied the number of practice exams that they completed across the different exams (the vast majority did so). Since students in the Control group were not asked to set goals, we estimate the effect of completing a practice exam uncontaminated by any effects of our goal-setting intervention.

The fixed effects estimates reported in Table 6 suggest that completing a practice exam increased the performance of students in the Control group by 1.486 points. If we multiply this estimate by the effect of goal setting on the number of practice exams completed $(0.491$ exams, from the first column of Table 3), we predict an effect of goal setting on performance of 0.730 points. This is remarkably close to the effect of goal setting on performance that we estimated previously from a treatment-control comparison of the students in the task-based goals experiment (0.742 points, from the first column of Panel I of Table 5). The equivalent calculations using our estimates for male students and for female students also line up reasonably well: for males the predicted performance effect of task-based goal setting is 1.241 points $(1.389 \times$ 0.893 ) versus an estimated effect of 1.787 points, while for female students the predicted effect of task-based goal setting is 0.247 points $(1.579 \times 0.156)$ versus an estimated effect of -0.128 points. Overall, our fixed effects estimates of the performance returns to completing practice exams support the hypothesis that the increase in task completion induced by task-based goal setting caused the improvement in student performance in the course. ${ }^{18}$

\footnotetext{
${ }^{18}$ Further evidence for the hypothesis that the increase in task completion induced by task-based goal setting caused the improvement in student performance comes from results showing that goal-setting did not affect another aspect of student behavior: participation in the course. In more detail, we construct an index of course participation, which measures the proportion of course components that a student completed weighted by the importance of each component in determining total points score in the course. We regress our index of course participation on an indicator of the student having been randomly allocated to the Treatment group in the task-
} 
Students in the Control group of the task-based goals experiment

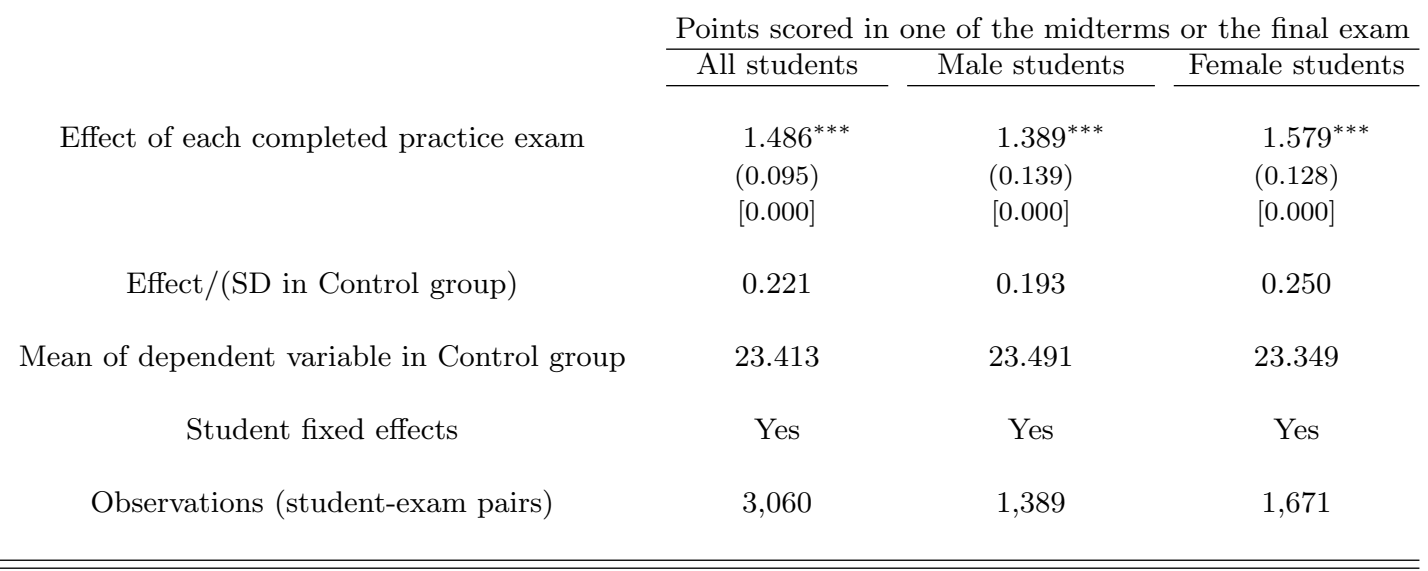

Notes: Each column reports fixed effects panel regressions of points scored in one of the midterms or the final exam on the number of practice exams completed in preparation for that midterm or final exam. Each student-exam pair is an observation (giving three observations per student). We include a fixed effect for each student, and the fixed effects absorb any effects of student characteristics on student performance. The sample includes only students from the Control group of the task-based goals experiment, who were not asked to set goals. 'SD in Control group' refers to the standard deviation of the dependent variable in the Control group. Heteroskedasticity-consistent standard errors (with clustering at the student level) are shown in round brackets and two-sided $p$-values are shown in square brackets. ${ }^{*},{ }^{* *}$ and ${ }^{* * *}$ denote, respectively, significance at the $10 \%, 5 \%$ and $1 \%$ levels (two-sided tests).

Table 6: Fixed effects estimates of the effect of completed practice exams on student performance

based goals experiment. We find that the effects of the treatment on course participation are small and far from being statistically significant. The $p$-values for OLS regressions of this index on the treatment are $0.668,0.367$ and 0.730 for, respectively, all students, male students, and female students. 


\section{Results of the performance-based goals experiment}

In this section we present the results of the performance-based goals experiment. Table 7 shows that performance-based goals had positive but small and statistically insignificant effects on student performance in the course. We first explain the structure of the table and we then describe the results reported in the table.

As in Section 3.2, we consider three measures of performance: (i) credit in the course, measured by students' total points score in the course (out of one hundred) that determines their letter grade; (ii) the probability that students achieved an A- or better; and (iii) the probability that students achieved a $\mathrm{B}+$ or better. ${ }^{19}$ The first column of Table 7 reports ordinary least squares (OLS) regressions of credit on an indicator for the student having been randomly allocated to the Treatment group in the performance-based goals experiment. The second column, titled 'Median', reports unconditional quantile regressions for the median of credit on the same indicator. ${ }^{20}$ The third and fourth columns report OLS regressions of, respectively, an indicator for the student having achieved an A- or better and an indicator for the student having achieved a $\mathrm{B}+$ or better on the same indicator as in the first two columns. The second row in each panel reports the effect size as a proportion of the standard deviation of the dependent variable in the Control group in the performance-based goals experiment, while the third row reports the average of the dependent variable in the same Control group.

We can see from Panel I of Table 7 that for the whole sample in the performance-based goals experiment asking students to set performance-based goals had positive but small and statistically insignificant effects on student performance in the course. The $p$-values are never close to the thresholds for statistical significance at conventional levels. Within the performancebased goals experiment, neither goals for letter grades in the course nor goals for scores in the two midterms and the final exam had a statistically significant effect on student performance. ${ }^{21}$ We continue to find statistically insignificant effects when we break the sample down by gender in Panels II and III. The regressions in Table 7 control for student characteristics: when we do not condition on student characteristics, we continue to find no statistically significant effects (see Table SWA.5 in Supplementary Web Appendix I).

In line with previous correlational studies (see the Introduction), we find that students who set ambitious performance-based goals performed better. Conditional on student characteristics, the correlation in our sample between course performance (measured by total number of points scored out of one hundred) and the level of the goal is $0.203(p=0.000)$ for students who set performance-based goals. The difference between the strong positive correlation based on non-experimental variation in our sample and the small and statistically insignificant causal effects that we estimate suggests that correlational analysis gives a misleading impression of the effectiveness of performance-based goals.

\footnotetext{
${ }^{19} \mathrm{~B}+$ was the median letter grade across the four semesters of our study.

${ }^{20}$ The median results were obtained using the estimator of Firpo et al. (2009), which delivers the effect of the treatment on the unconditional median of credit.

${ }^{21}$ For each of the four specifications reported in Panel I, and using the ten-percent-level criterion, we find no statistically significant effect of either type of performance-based goal, and we find no statistically significant difference between the effects of the two types of goal. For the case of OLS regressions of credit on the treatment, the $p$-values for the two effects and the difference are, respectively, $p=0.234, p=0.856$, and $p=0.386$.
} 
Panel I: All students in the performance-based goals experiment

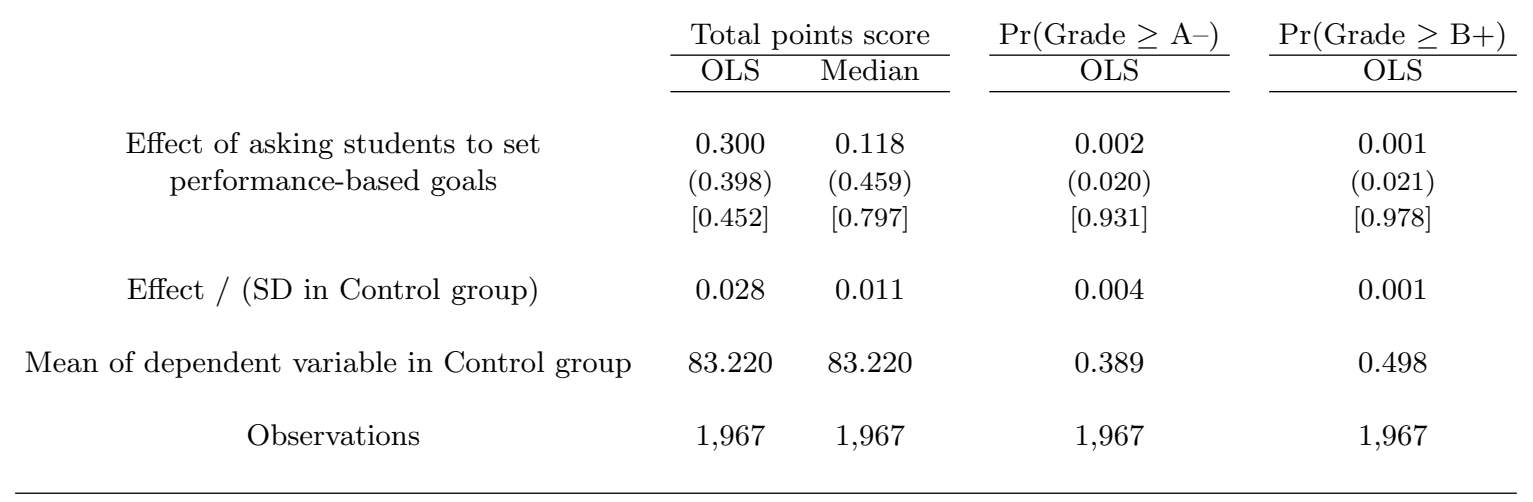

Panel II: Male students in the performance-based goals experiment

\begin{tabular}{|c|c|c|c|c|}
\hline & \multicolumn{2}{|c|}{ Total points score } & \multirow{2}{*}{$\frac{\operatorname{Pr}\left(\text { Grade } \geq A^{-}\right)}{\text {OLS }}$} & \multirow{2}{*}{$\frac{\operatorname{Pr}(\text { Grade } \geq B+)}{\text { OLS }}$} \\
\hline & OLS & Median & & \\
\hline $\begin{array}{l}\text { Effect of asking students to set } \\
\text { performance-based goals }\end{array}$ & $\begin{array}{c}0.430 \\
(0.594) \\
{[0.469]}\end{array}$ & $\begin{array}{c}0.576 \\
(0.618) \\
{[0.352]}\end{array}$ & $\begin{array}{c}0.008 \\
(0.030) \\
{[0.796]}\end{array}$ & $\begin{array}{c}0.028 \\
(0.030) \\
{[0.352]}\end{array}$ \\
\hline Effect / (SD in Control group) & 0.041 & 0.055 & 0.016 & 0.057 \\
\hline Mean of dependent variable in Control group & 83.644 & 83.644 & 0.403 & 0.511 \\
\hline Observations & 933 & 933 & 933 & 933 \\
\hline
\end{tabular}

Panel III: Female students in the performance-based goals experiment

\begin{tabular}{|c|c|c|c|c|}
\hline & \multicolumn{2}{|c|}{ Total points score } & \multirow{2}{*}{$\frac{\operatorname{Pr}\left(\text { Grade } \geq \mathrm{A}^{-}\right)}{\text {OLS }}$} & \multirow{2}{*}{$\frac{\operatorname{Pr}(\text { Grade } \geq B+)}{\text { OLS }}$} \\
\hline & OLS & Median & & \\
\hline \multirow{3}{*}{$\begin{array}{l}\text { Effect of asking students to set } \\
\text { performance-based goals }\end{array}$} & 0.181 & -0.330 & -0.004 & -0.025 \\
\hline & $(0.536)$ & $(0.642)$ & $(0.028)$ & $(0.029)$ \\
\hline & {$[0.736]$} & {$[0.607]$} & {$[0.894]$} & {$[0.392]$} \\
\hline Effect / (SD in Control group) & 0.017 & -0.031 & -0.008 & -0.049 \\
\hline Mean of dependent variable in Control group & 82.864 & 82.864 & 0.377 & 0.487 \\
\hline Observations & 1,034 & 1,034 & 1,034 & 1,034 \\
\hline
\end{tabular}

Notes: The first column reports OLS regressions of total points score on an indicator for the student having been randomly allocated to the Treatment group in the performance-based goals experiment. The second column reports unconditional quantile regressions for the median of total points score on the same indicator. The third and fourth columns report OLS regressions of, respectively, an indicator for the student having achieved an Aor better and an indicator for the student having achieved a B+ or better on the same indicator as in the first two columns. 'SD in Control group' refers to the standard deviation of the dependent variable in the Control group. We control for student characteristics as explained in the notes to Table 5. Heteroskedasticity-consistent standard errors are shown in round brackets and two-sided $p$-values are shown in square brackets. ${ }^{*},{ }^{* *}$ and ${ }^{* * *}$ denote, respectively, significance at the $10 \%, 5 \%$ and $1 \%$ levels (two-sided tests).

Table 7: Effects of performance-based goals on student performance 


\section{$5 \quad$ Using theory to interpret our experimental findings}

\subsection{Motivation}

In this section we suggest some hypotheses for our findings. For each type of goal (performanceand task-based), our approach is to write down a simple model of goal setting and then use this to generate possible hypotheses. We acknowledge that these models are not the only ones that we could have used, but we are not aiming to test theory. Rather, we are using theory to guide the analysis and interpretation of our findings.

Our models build on Koch and Nafziger (2011) and are inspired by two key concepts in behavioral economics: present bias and loss aversion. The concept of present bias captures the idea that people lack control because they place a high weight on current utility (Strotz, 1956). ${ }^{22}$ More specifically, a present-biased discounter places more weight on current utility relative to utility $n$ periods in the future than she does on utility at future time $t$ relative to utility at time $t+n$. This implies that present-biased discounters exhibit time inconsistency, since their time preferences at different dates are not consistent with one another. In the context of education, a present-biased student might set out to exert her preferred level of effort, but when the time comes to attend class or review for a test she might lack the self-control necessary to implement these plans. ${ }^{23}$ Strotz (1956) and Pollak (1968) were the first to analyze how time-inconsistent agents make choices anticipating the different time preferences of their future selves. Building on this insight, Strotz (1956) noted that present-biased agents can mitigate their self-control problem by using commitment devices to bind their future self. ${ }^{24}$

The concept of loss aversion captures the idea that people dislike falling behind a salient reference point (Kahneman and Tversky, 1979). ${ }^{25}$ In the context of education, a loss-averse student might work particularly hard in an attempt to achieve a salient reference point (e.g., a particular grade in her course).

Together, the literatures on present bias and loss aversion suggest that self-set goals might serve as an effective commitment device. Specifically, self-set goals might act as salient reference points, helping present-biased agents to mitigate their self-control problem and so steer their effort toward its optimal level. Indeed, Koch and Nafziger (2011) developed a model of goal setting based on this idea that we build on here. Unlike us, however, Koch and Nafziger (2011) did not explore the effectiveness of different types of goals. ${ }^{26}$

\footnotetext{
${ }^{22}$ Present bias has been proposed as an explanation for aspects of many behaviors such as addiction (Gruber and Köszegi, 2001), early retirement (Diamond and Köszegi, 2003), smoking (Khwaja et al., 2007), welfare program participation (Fang and Silverman, 2009) and credit card borrowing (Meier and Sprenger, 2010). See Dhami (2016) for a recent comprehensive survey of the literature on present bias.

${ }^{23}$ Under standard (i.e., exponential) discounting this self-control problem disappears.

${ }^{24}$ We provide examples of such commitment devices in footnote 2 in the Introduction.

${ }^{25}$ Loss aversion has been proposed as a foundation of a number of phenomena such as the endowment effect (Kahneman et al., 1990), small-scale risk aversion (Rabin, 2000), the disposition effect (Genesove and Mayer, 2001), and the role of expectations in single-agent decision-making (Bell, 1985; Köszegi and Rabin, 2006) and in strategic interactions (Gill and Stone, 2010; Gill and Prowse, 2012).

${ }^{26}$ Koch and Nafziger (2011)'s model also differs from our models in that agents in their model choose from only two possible effort levels, while our models allow students to choose both effort and goals from a continuum. Again without exploring the effectiveness of different types of goals, Jain (2009) also studies theoretically how present-biased agents can use goals as reference points; in Jain (2009)'s model utility is discontinuous at the reference point, rather than kinked as in Kahneman and Tversky (1979)'s model of loss aversion that we and Koch and Nafziger (2011) use. Heath et al. (1999) and Wu et al. (2008) linked goals to loss aversion, but did not make the connection to present bias. Finally, a related theoretical literature studies expectations as goals
} 


\subsection{Performance-based goal setting}

\subsubsection{Simple model}

We start by building a simple model of performance-based goal setting. In Section 5.2.2 we use the model to suggest three hypotheses for why performance-based goals might not be very effective in the context that we studied.

At period one the student sets a goal $g \geq 0$ for performance $f \geq 0$; we call the student at period one the student-planner. At period two the student chooses effort $e \geq 0$; we call the student at period two the student-actor. The student-actor incurs a cost of effort $C(e)=c e^{2} / 2$, with $c>0$. At period three performance is realized and the student incurs any disutility from failing to achieve her goal; we call the student at period three the student-beneficiary. Performance increases one-to-one in effort exerted by the student-actor at period two, i.e., $f(e)=$ $e$, and the student-beneficiary's utility increases one-to-one in performance. ${ }^{27}$ The studentbeneficiary is loss averse around her goal: she suffers goal disutility that depends linearly on how far performance falls short of the goal set by the student-planner at period one. The studentbeneficiary's goal disutility is given by $-l \max \{g-f(e), 0\}$. The parameter $l>0$ captures the strength of loss aversion, which in our context we call the 'strength of goal disutility'. ${ }^{28,29}$

The student is present biased. In particular, the student exhibits quasi-hyperbolic discounting, with $\beta \in(0,1)$ and $\delta \in(0,1]$ : the student discounts utility $n$ periods in the future by a factor $\beta \delta^{n}{ }^{30}$ Under quasi-hyperbolic discounting the student-planner discounts period-two utility by a factor $\beta \delta$ and period-three utility by a factor $\beta \delta^{2}$, and so discounts period-three utility by $\delta$ relative to period-two utility. The student-actor, on the other hand, discounts period-three utility by $\beta \delta$ relative to immediate period-two utility. Since $\beta \delta<\delta$, the student-planner places more weight on utility from performance at period three relative to the cost of effort at period two than does the student-actor.

As a result of this present bias, and in the absence of a goal, the student-planner's desired effort is higher than the effort chosen by the student-actor: that is, the student exhibits a self-control problem due to time inconsistency. ${ }^{31}$ We formalize this as follows:

(Suvorov and Van de Ven, 2008; Hsiaw, 2013; Hsiaw, 2016; Koch and Nafziger, 2016).

${ }^{27} \mathrm{Using}$ one-to-one relationships instead of more general linear relationships is without loss of generality.

${ }^{28}$ Specifically, $l$ measures the psychological loss from failing to achieve the goal relative to 'material' utility.

${ }^{29}$ This formulation implies that the student suffers disutility from failing to achieve her goal. However, it also implies that she enjoys no elation from exceeding the goal. This latter assumption can be justified in two ways. First, the more parsimonious one-parameter model of loss aversion allows us to gain useful insights into the effectiveness of goal setting. Second, if students enjoyed elation from exceeding their goals, they would have a strategic incentive to set low goals in order to enjoy the utility boost from exceeding them, but we do not see evidence that this motivation is an important driver of behavior in our data.

${ }^{30}$ Laibson (1997) was the first to apply the analytically tractable quasi-hyperbolic (or 'beta-delta') model of discounting to analyze the choices of present-biased time-inconsistent agents. Like us, Laibson (1997) finds the equilibria of a dynamic game among a sequence of temporal selves.

${ }^{31}$ When $g=0$, goal disutility is zero since $\max \{g-f(e), 0\}=0$, and so $g=0$ is equivalent to the absence of a goal. 


\section{Remark 1}

In the absence of a goal the student exhibits time inconsistency:

(i) The student-actor chooses effort $\underline{e}=\beta \delta / c$.

(ii) The student-planner would like the student-actor to exert effort $\hat{e}=\delta / c>\underline{e}$.

Proof. See Supplementary Web Appendix III.1.

To alleviate her self-control problem due to time-inconsistency, the student-planner might choose to set a goal. Goals can be effective by increasing the student-actor's marginal incentive to work in order to avoid the goal disutility that results from failing to achieve the goal.

To demonstrate this point, we solve for the subgame-perfect Nash equilibria of the game outlined above, in which the players are the student-planner and student-actor. We do so by backward induction. First, we analyze the effort choice of the student-actor at period two for any goal set by the student-planner at period one. The student-actor's utility is given by:

$$
\begin{aligned}
u_{a c t}(e \mid g) & =\beta \delta[f(e)-l \max \{g-f(e), 0\}]-C(e) \\
& =\beta \delta[e-l \max \{g-e, 0\}]-\frac{c e^{2}}{2} .
\end{aligned}
$$

Proposition 1 shows how the student-actor's effort responds to the goal.

\section{Proposition 1}

Let $\bar{e}=\beta \delta(1+l) / c$ and recall from Remark 1 that $\underline{e}=\beta \delta / c<\bar{e}$ denotes the student-actor's effort in the absence of a goal.

(i) When $g \leq \underline{e}$, the student-actor exerts effort $e^{*}=\underline{e}$.

(ii) When $g \in[\underline{e}, \bar{e}]$, the student-actor exerts effort $e^{*}=g$.

(iii) When $g \geq \bar{e}$, the student-actor exerts effort $e^{*}=\bar{e}$.

Proof. See Supplementary Web Appendix III.1.

Proposition 1 tells us that, perhaps unsurprisingly, the goal does not raise effort when it is set lower than the student-actor's optimal level of effort in the absence of a goal $\underline{e}$. Intermediate goals are effective: intermediate goals induce the student-actor to work hard enough to achieve the goal in order to avoid disutility from falling short of the goal. Beyond a certain point the marginal cost of effort outweighs the marginal reduction in goal disutility, and so the goal induces an increase in effort only to an upper bound $\bar{e}$. Goals above the upper bound leave the student-actor to suffer some goal disutility. This upper bound increases as the time-inconsistency problem becomes less severe (higher $\beta$ ) and as the strength of goal disutility $l$ goes up.

Having established how the student-actor's effort responds to any goal set by the studentplanner, we now consider the student-planner's optimal choice of goal. Letting $e^{*}(g)$ represent the student-actor's optimal effort given a goal $g$, the student-planner's utility is given by:

$$
\begin{aligned}
u_{p l a n}\left(g \mid e^{*}(g)\right) & =\beta \delta^{2}\left[f\left(e^{*}(g)\right)-l \max \left\{g-f\left(e^{*}(g)\right), 0\right\}\right]-\beta \delta C\left(e^{*}(g)\right) \\
& =\beta \delta^{2}\left[e^{*}(g)-l \max \left\{g-e^{*}(g), 0\right\}\right]-\beta \delta \frac{c\left[e^{*}(g)\right]^{2}}{2} .
\end{aligned}
$$




\section{Proposition 2}

Recall from Remark 1 that $\underline{e}=\beta \delta / c$ and $\hat{e}=\delta / c$ denote, respectively, student-actor effort and student-planner desired effort in the absence of a goal.

Recall from Proposition 1 that $\bar{e}=\beta \delta(1+l) / c$ denotes maximal student-actor effort in the presence of a goal.

(i) The optimal choice of goal for the student-planner is given by $g^{*}=\min \{\hat{e}, \bar{e}\}$.

(ii) When $\beta(1+l)<1, g^{*}=\bar{e}$.

(iii) When $\beta(1+l) \geq 1, g^{*}=\hat{e}$.

(iv) Effort of the student-actor $e^{*}=g^{*}>\underline{e}$, and so the student-actor works harder than in the absence of goal.

Proof. See Supplementary Web Appendix III.1.

We know from Proposition 1 that goals in the range $[\underline{e}, \bar{e}]$ induce the student-actor to work to achieve the goal, but that higher goals are ineffective in raising effort above $\bar{e}$. Thus, the student-planner will never set a goal higher than $\bar{e}$, since higher goals are not effective but leave the student-actor to suffer some goal disutility from failing to achieve the goal. If the studentplanner could simply impose a level of effort on the student-actor, then we know from Remark 1 that she would choose $\hat{e}$. When $\beta(1+l)$ is big enough, $\hat{e} \leq \bar{e}$, and so the student-planner achieves her desired level of effort by setting $g^{*}=\hat{e}$. This case holds when the time-inconsistency problem is not too severe (high $\beta$ ) or the strength of goal disutility $l$ is sufficiently high. When her desired level of effort is not achievable, the student-planner sets $g^{*}=\bar{e}$, and so the student-planner uses the goal to induce as much effort from the student-actor as she is able to. In either case, the optimal goal induces the student to work harder than she would in the absence of a goal and the student always achieves her goal in equilibrium.

\subsubsection{Why might performance-based goals not be very effective?}

This model of performance-based goal setting suggests that performance-based goals can improve course performance. However, our experimental data show that performance-based goals had a positive but small and statistically insignificant effect on student performance (Table 7). In our view, the simple model sketched above suggests three hypotheses for why performance-based goals might not be very effective in the context that we studied (we view these hypotheses as complementary).

\section{Timing of goal disutility}

In the simple model, the student works in period two and experiences any goal disutility from failing to achieve her performance-based goal in period three (i.e., when performance is realized). This temporal distance will dampen the motivating effect of the goal. Formally, the studentactor discounts goal disutility by a factor $\beta \delta<1$; in the expression for maximal student-actor effort in the presence of a goal, $\bar{e}$, the parameter measuring the strength of goal disutility, $l$, is multiplied by this discount factor (see Proposition 2). Even when the temporal distance between effort and goal disutility is modest, the timing of goal disutility dampens the effectiveness of 
performance-based goals because quasi-hyperbolic discounters discount the near future relative to the present by a factor $\beta$ even if $\delta \approx 1$ over the modest temporal distance.

\section{Overconfidence}

In the simple model, students understand perfectly the relationship between effort and performance. In contrast, the education literature suggests that students face considerable uncertainty about the educational production function, and that this uncertainty could lead to students holding incorrect beliefs about the relationship between effort and performance (e.g., Romer, 1993, and Fryer, 2013). Furthermore, the broader behavioral literature shows that people tend to be overconfident when they face uncertainty (e.g., Weinstein, 1980, Camerer and Lovallo, 1999, and Park and Santos-Pinto, 2010). The behavioral literature also provides a number of theoretical underpinnings for overconfidence (e.g., Brunnermeier and Parker, 2005, Johnson and Fowler, 2011, and Gossner and Steiner, 2016).

Suppose that some students are overconfident. An overconfident student believes that the production function is given by $f(\cdot)$, when in fact performance is given by $h f(\cdot)$ with $h \in(0,1)$ for any value of effort. An overconfident student will act as if the production function is given by $f(\cdot)$, and so the model in Section 5.2.1 describes her choice of goal and effort. However, the student's actual performance with goal setting and in the absence of a goal will be a proportion $h$ of that expected by the student. As a result, the impact of performance-based goal setting on performance will be reduced by this proportion $h$. Furthermore, the overconfident student will unexpectedly fail to achieve her performance-based goal.

\section{Performance uncertainty}

In the simple model, the student knows for sure how her effort translates into performance (i.e., the relationship between effort and performance involves no uncertainty). As such, her goal is always achieved in equilibrium. In practice, the relationship between effort and performance is likely to be noisy and, as in our experiment, performance-based goals are not always reached. The student could face uncertainty about her own ability or about the productivity of work effort. The student might also get unlucky: for instance, the draw of questions on the exam might be unfavorable or the student might get sick near the exam.

To introduce uncertainty about performance in a straightforward way, suppose that the student is risk neutral and that with known probability $\pi \in(0,1)$ her effort translates into performance according to $f(\cdot)$ as in Section 5.2.1, while with probability $1-\pi$ performance $f=0$ (since we assume that $\pi$ is known, the student is neither overconfident nor underconfident). ${ }^{32}$

The formal details of the analysis are relegated to Supplementary Web Appendix III.3. The uncertainty directly reduces the student-actor's marginal incentive to exert effort, which reduces by a factor $\pi$ the equilibrium goal and equilibrium effort with and without goal setting. However, this general reduction in incentives is not the only effect of uncertainty: performance-based goals become risky because when performance turns out to be low the student fails to achieve her performance-based goal and so suffers goal disutility that increases in the goal (as in the simple

\footnotetext{
${ }^{32}$ We can think of $f=0$ as a baseline level of performance that the student achieves with little effort even in the absence of goal setting.
} 
model, goals are never exceeded in equilibrium). In contrast to the case of overconfidence discussed above, goal failure is not unexpected: the student facing uncertainty anticipates that she will not always achieve her performance-based goal.

Anticipating the goal disutility suffered when performance turns out to be low, the studentplanner further scales back the performance-based goal that she sets for the student-actor, which reduces the effectiveness of performance-based goal setting. Formally, this extra effect adds the second term to the numerator in the expression for $\tilde{e}$ in Proposition SWA.4 in Supplementary Web Appendix III.3. ${ }^{33,34}$

\subsection{Task-based goal setting}

\subsubsection{Simple model}

We now model task-based goal setting. At period one the student-planner sets a goal $g \geq 0$ for the number of units of the task to complete $a \geq 0$. We call $a$ the 'level of task completion'. At period two the student-actor chooses the level of task completion $a$. The student-actor incurs a cost of task completion $C(a)=\kappa a^{2} / 2$, with $\kappa>0$. Furthermore, at period two the loss-averse student-actor suffers goal disutility that depends linearly on how far the level of task completion falls short of the goal set by the student-planner at period one: she suffers goal disutility of $-\lambda \max \{g-a, 0\}$, where the loss parameter $\lambda$ captures the strength of goal disutility. ${ }^{35}$ At period three performance is realized. Performance increases linearly in the level of task completion: $f(a)=\theta a$, with $\theta>0$; while the student-beneficiary's utility increases one-to-one in performance. ${ }^{36}$ The present-biased student exhibits quasi-hyperbolic discounting as described in Section 5.2.1. Thus the student-actor's utility is given by:

$$
\begin{aligned}
u_{a c t}(a \mid g) & =\beta \delta f(a)-[\lambda \max \{g-a, 0\}+C(a)] \\
& =\beta \delta \theta a-\left[\lambda \max \{g-a, 0\}+\frac{\kappa a^{2}}{2}\right] ;
\end{aligned}
$$

\footnotetext{
${ }^{33}$ Proposition SWA.4 in Supplementary Web Appendix III.3 focuses on the case in which uncertainty is not too big. When the student faces a lot of uncertainty, the extra effect could lead the student-planner to prefer not to set a goal at all.

${ }^{34}$ This scaling back of goals is not necessarily at odds with the fact that the performance-based goals that we see in the data appear ambitious. First, the goal will appear ambitious relative to average achievement because, as noted above, when performance turns out to be low the student fails to achieve her goal. Second, without any scaling back the goals might have been even higher. Third, the overconfidence that we discuss above could keep the scaled-back goal high. Fourth, we explain in Section 5.3.4 below that students likely report as their goal an 'aspiration' that is only relevant if, when the time comes to study, the cost of effort turns out to be particularly low: the actual cost-specific goal that the student aims to hit could be much lower than this aspiration.

${ }^{35}$ As explained in footnote 29 , we do not include any elation from exceeding the goal. We use new notation for the parameter that measures the strength of goal disutility $\lambda$ because the units used to measure the level of task completion are different from the performance units in Section 5.2.1. Note also that goal disutility is incurred at period two here because the student-actor observes how far she is from the task-based goal immediately when she stops working on the task. For performance-based goals in Section 5.2.1 goal disutility is incurred at period three when performance is realized.

${ }^{36}$ Units of performance and units of task completion are both defined externally, and so we need to introduce the parameter $\theta$ to model a linear relationship between them.
} 
and, letting $a^{*}(g)$ represent the student-actor's optimal level of task completion given a goal $g$, the student-planner's utility is given by:

$$
\begin{aligned}
u_{\text {plan }}\left(g \mid a^{*}(g)\right) & =\beta \delta^{2} f\left(a^{*}(g)\right)-\beta \delta\left[\lambda \max \left\{g-a^{*}(g), 0\right\}+C\left(a^{*}(g)\right)\right] \\
& =\beta \delta^{2} \theta a^{*}(g)-\beta \delta\left[\lambda \max \left\{g-a^{*}(g), 0\right\}+\frac{\kappa\left[a^{*}(g)\right]^{2}}{2}\right] .
\end{aligned}
$$

When we solve the game by backward induction, we get results that are qualitatively similar to those for performance-based goals in Section 5.2.1. The formal results and proofs are relegated to Supplementary Web Appendix III.2. The three relevant thresholds now become:

$$
\underline{a}=\frac{\beta \delta \theta}{\kappa} ; \quad \hat{a}=\frac{\delta \theta}{\kappa}>\underline{a} ; \quad \bar{a}=\frac{\beta \delta \theta+\lambda}{\kappa}>\underline{a} .
$$

Mirroring Remark 1, in the absence of a goal the present-biased student exhibits a self-control problem due to time inconsistency: the student-actor chooses a level of task completion $\underline{a}$, which is smaller than the student-planner's desired level of task completion $\hat{a}$. The upper bound on student-actor task completion in the presence of a goal is given by $\bar{a}$. Mirroring Proposition 1 , this upper bound increases as the time-inconsistency problem becomes less severe (higher $\beta$ ) and as the strength of goal disutility $\lambda$ goes up. Mirroring Proposition 2, the optimal choice of goal for the student-planner is given by $g^{*}=\min \{\hat{a}, \bar{a}\}$ and the optimal goal induces a level of task completion by the student-actor of $a^{*}=g^{*}>\underline{a}$; the optimal goal induces a higher level of task completion than in the absence of a goal, and the student always achieves her goal in equilibrium. ${ }^{37}$ The goal increases the level of task completion as well as improving course performance.

\subsubsection{Why were task-based goals effective?}

Our experimental data show that task-based goals improved task completion and course performance (see Table 3 for the effect on task completion and Table 5 for the effect on course performance) ${ }^{38}$ How might we account for these findings, given our analysis of why performance-based goals might not be very effective? In our view, an obvious answer is that with task-based goal setting, the three factors that reduce the effectiveness of performance-based goals (Section 5.2.2) are of lesser importance or do not apply at all.

\section{Timing of goal disutility}

In the case of task-based goal setting, any goal disutility from failing to achieve the task-based goal is suffered immediately when the student stops working on the task in period two. Thus, unlike the case of performance-based goal setting discussed in Section 5.2.2, there is no temporal

\footnotetext{
${ }^{37}$ When $\beta \delta \theta+\lambda \geq \delta \theta, \hat{a} \leq \bar{a}$, and so the student-planner achieves her desired level of task completion by setting $g^{*}=\hat{a}$. Similarly to Proposition 2, this case holds when the time-inconsistency problem is not too severe (high $\beta$ ) or the strength of goal disutility $\lambda$ is sufficiently high.

${ }^{38}$ It is possible that some students in the Control group (who were not invited to set goals) might already use goals as a commitment device. However, since we find that task-based goals are successful at increasing performance, we conclude that many students in the Control group did not use goals or set goals that were not fully effective. We note that asking students to set goals might make the usefulness of goal setting as a commitment device more salient and so effective. Reminding students of their goal, as we did, might also help to make them more effective.
} 
distance that dampens the motivating effect of the goal. Formally, in the expression for maximal task completion in the presence of a goal, $\bar{a}$, the parameter measuring the strength of goal disutility, $\lambda$, is undiscounted (see (9)).

\section{Overconfidence}

As discussed in Section 5.2.2, overconfidence reduces the effectiveness of goal setting. Recall that an overconfident student acts as if the production function is given $f(\cdot)$, when in fact performance is given by $h f(\cdot)$, which reduces the impact of goal setting on performance by the proportion $h$. In the case of task-based goal setting, this effect is mitigated if practice exams direct students toward productive tasks: in that case $h$ goes up. Plausibly, teachers have better information about which tasks are likely to be productive, and asking students to set goals for productive tasks is one way to improve the power of goal setting for overconfident students.

Instead of improving the power of goal setting by directing overconfident students toward productive tasks, it is conceivable that task-based goals improved performance via another channel: signaling to students in the Treatment group that practice exams were an effective task. But we think this is highly unlikely. First, we were careful to make the practice exams as salient as possible to the Control group. Second, students in the Control group in fact completed many practice exams. Third, it is hard to understand why only men would respond to the signal.

\section{Performance uncertainty}

In Section 5.2.2, we introduced uncertainty about performance. It is straightforward to add performance uncertainty into the simple model of task-based goal setting outlined in Section 5.3.1. The formal details of the analysis are relegated to Supplementary Web Appendix III.3. The important point to note is that even with uncertainty about performance, the student continues to achieve her task-based goal: there is no 'task uncertainty'. The reason is that the student-actor controls the number of units of the task that she completes and so can guarantee to hit her task-based goal. Thus, unlike the case of performance-based goals with uncertainty, the student has no reason to scale back her task-based goal to reduce goal disutility in the event that the goal is not reached.

\subsubsection{Why were task-based goals more effective for men than for women?}

Our data show that task-based goals are more effective for men than for women. More specifically: in the Control group without goal setting men completed fewer practice exams than women (Table 4); and task-based goals increased performance and the number of practice exams completed more for men than for women (Tables 5 and 4 respectively). In the context of our simple model of task-based goal setting (Section 5.3.1), one hypothesis that could explain this finding is that the male students in our sample are more present biased than the female students (i.e., the men have a lower $\beta$ parameter). Existing empirical evidence supports the idea that men may have less self-control and be more present biased than women. ${ }^{39}$ Interestingly, in a

\footnotetext{
${ }^{39}$ In the Introduction we referred to evidence from educational environments that females have more self-control than males (e.g., Duckworth and Seligman, 2005, Buechel et al., 2014, and Duckworth et al., 2015). Consistent with gender differences in self-control, incentivized experiments suggest that men may be more present biased than women. When the earliest payment is immediate (no 'front-end delay'), which provides a test of quasi-hyperbolic
} 
laboratory experiment in which goals were set by the experimenter rather than by the subjects themselves, Smithers (2015) finds that goals increased the work performance of men but not that of women.

To understand the role of present bias, first note that the student-actor's level of task completion in the absence of a goal $\underline{a}$ is increasing in $\beta$ : the more present biased the student, the fewer practice exams he or she completes without a goal. Thus, if men are more present biased than women, then their higher degree of present bias will push down their level of task completion in the Control group relative to that of women. Second, the increase in task completion induced by goal setting also depends on the degree of present bias: in particular, the difference between the student-planner's desired level of task completion $\hat{a}$ and the student-actor's level of task completion in the absence of a goal $\underline{a}$ is decreasing in $\beta$. Thus, if men are more present biased than women, then goal setting will tend to be more effective at increasing the number of practice exams that men complete, which in turn feeds into a larger effect on performance.

\subsubsection{Why were task-based goals not always achieved?}

In the simple models outlined in Sections 5.2.1 and 5.3.1 goals are always achieved. In Section 5.2.2 we explained how overconfidence and performance uncertainty can result in a student's failure to achieve her performance-based goal. A puzzle remains: even though task-based goals are more frequently achieved than performance-based goals, task-based goals are not always achieved (Table 2).

Failure to achieve task-based goals emerges naturally if we relax the assumption that costs are known with certainty. In particular, suppose that the student-actor's cost parameter ( $c$ or $\kappa)$ can be high or low, and that the student-actor draws her cost parameter in period two before she decides how hard to work (the analysis extends naturally to any number of possible cost draws). For example, the cost uncertainty could be driven by uncertainty about the set of leisure activities available to the student during the time that she planned to study. Anticipating this cost uncertainty, we allow the student-planner to set a goal for both possible cost draws. The optimal goal for a given cost draw is just as in the models in Sections 5.2.1 and 5.3.1 with no cost uncertainty, and the student-actor always works hard enough to achieve the cost-specific goal. Of course, we ask the student to report only one goal: we assume here that the student-planner reports to us only her goal for the low-cost draw. This goal is like an aspiration: if the cost turns out to be high, the goal is scaled down to reflect the higher cost. Because we as the experimenter observe only the reported aspiration, when the cost is high we observe a failure to achieve the reported aspiration, even though the student achieves her cost-specific goal.

discounting, McLeish and Oxoby (2007), Meier and Sprenger (2010) and Prince and Shawhan (2011) find that men are more present biased than women, while Tanaka et al. (2010) find no gender difference in present bias for rural Vietnamese (in Meier and Sprenger, 2010, when controls that include endogenous behavioral measures are included men remain more present biased than women, but the effect is no longer statistically significant). When rural Malawians are given an unexpected opportunity to reverse an earlier commitment, Giné et al. (forthcoming) find that men are more likely to reverse their earlier choice and instead choose an earlier but smaller payment. When the earliest payment is not immediate ('front-end delay'), no gender differences have been found (see Bauer and Chytilová, 2013, for rural Indians and Harrison et al., 2005, where the earliest payment is delayed by a month). 


\section{Conclusion}

Our experimental findings suggest that task-based goal setting is an intervention that can improve college outcomes: asking students to set goals for the number of practice exams to complete increased the number of practice exams that students completed and increased course performance. Further empirical analysis supports the most obvious explanation for this finding: task-based goal setting induces greater task-specific investment, which in turn improves course performance.

This raises the question of how best to incorporate task-based goal setting into the college environment. Academic advising services could be a particularly promising vehicle for promoting the benefits of task-based goal setting. American colleges already offer a panoply of academic advising services to students. These include counselors and mentors, campus centers that students can visit, and student success programs and courses that students are encouraged or required to follow (e.g., as part of academic remediation activities). Students in receipt of these services are often advised that goal setting is an essential study skill. For example, the college that provides the course that we study has a "Teaching Center" that provides academic advising services to students. These services include online resources that recommend that students implement five "essential study strategies", one of which is to "Set Goals". Another example is CUNY's Accelerated Study in Associate Programs (ASAP), which encourages first-year students to attend seminars that explicitly cover goal setting, alongside other study skills (Scrivener et al., 2015). ${ }^{40}$

These academic advising services often present goal setting as one of many strategies that students might try. Moreover, they do not prescribe the particular types of goals that students should set. ${ }^{41}$ Our results suggest that advising services should consider giving greater prominence to task-based goal setting. For example, advisors could encourage students to set goals for the number of lectures that they will attend in a semester rather than the grade they will achieve on a course. Advisors could also encourage students to set task-based goals in consultation with course instructors, who have the information necessary to advise students on which tasks will likely be most productive (e.g., reviewing lecture notes versus studying the course textbook).

The most direct way to incorporate task-based goal setting into the college environment would be for instructors to design courses that promote task-based goal setting. In a traditional course format, an instructor could encourage students to set goals for particular tasks by devoting lecture time or a section of the syllabus to a discussion of study strategies. In a course that required students to complete certain tasks online (e.g., homework assignments or class discussion), the opportunity to set goals could be built into the technology used to deliver these course components (similarly to the way that we built goal setting into the surveys that preceded the online practice exams that students completed as part of the course that we studied). In a fully online course, it would be especially easy to incorporate task-based goal setting into the technology used to deliver course content. For example, students could be invited to set goals for the number of end-of-module questions they will answer correctly before progressing to the next module.

\footnotetext{
${ }^{40}$ The ASAP have received a lot of attention for their large effects on student retention (Scrivener et al., 2015).

${ }^{41}$ For example, the online resources provided by the "Teaching Center" in the college that provides the course that we study advise students to set goals that are Specific, Measurable, Attainable, Realistic and Timely (SMART). There is no mention of whether goals should be performance- or task-based.
} 
This discussion suggests that task-based goal setting could easily be incorporated into the college learning environment. Coupled with our analysis, this suggests that task-based goal setting is a low-cost, scaleable and feasible intervention that could improve college outcomes. This is a promising finding, and it suggests several lines of interesting future research. First, it would be interesting to conduct similar experiments in other types of colleges. For example, our subjects (who attend a four-year college) are likely more able than two-year college students (e.g., as reflected in SAT scores). If they also possess more self-control than these two-year college students, then goal setting might be even more effective at two-year colleges. Second, assuming that our findings generalize across settings, it would be interesting to examine the effects of selfset goals for other tasks such as attending class, contributing to online discussions or working through textbook chapters. This type of research could uncover important relationships between task characteristics and the effects of task-based goal-setting. For example, some tasks are public (e.g., attending class, contributing to online discussion) whereas others are private (e.g., working through textbook chapters); it would be useful to discover whether public or private tasks are more responsive to goal setting. ${ }^{42}$ A useful byproduct of this type of research is that it can advance our knowledge of the production function for course performance. Specifically, if task-based goal setting increases course performance only through the effects of goal setting on task-specific investments, then assignment to the goals treatment is an instrument that can be used to identify the performance effects of these investments. It would be interesting to compare the causal effects of different task-specific investments, such as attending class, working through lecture notes and completing practice exams. ${ }^{43}$

To summarize, we believe that our study marks an important step toward a better understanding of the role that self-set goals could play in motivating college students to work harder and perform better. Research in psychology and economics provides reason to expect that college students, like other agents in the economy, will lack self-control. Our results break new ground by suggesting that self-set goals can act as an effective commitment device that helps college students to self-regulate behavior and mitigate these self-control problems. Specifically, our empirical findings suggest that task-based goal setting could be an especially effective method of mitigating self-control problems and thereby improving college performance. Since task-based goal setting could easily be incorporated into the college environment, our findings have important implications for educational practice. As noted above, future research should probe the effects of task-based goal setting in other contexts and for other tasks.

\footnotetext{
${ }^{42}$ On the one hand, we might expect the costs of failing to meet goals to be larger for public tasks (e.g., if these are more salient to students). On the other hand, these costs may be lower if there is an "anti-nerd" class culture.

${ }^{43}$ There is already a small literature on the performance effects of attending class. For example, Dobkin et al. (2010) and Arulampalam et al. (2012) exploit quasi-experiments to estimate the effects of attendance on college course performance.
} 


\section{References}

Akın, Z. and Karagözoğlu, E. (forthcoming). The role of goals and feedback in incentivizing performance. Managerial and Decision Economics

Allan, B.M. and Fryer, R.G. (2011). The power and pitfalls of education incentives. Policy Paper, Hamilton Project

Angrist, J., Lang, D., and Oreopoulos, P. (2009). Incentives and services for college achievement: Evidence from a randomized trial. American Economic Journal: Applied Economics, 1(1): 136-163

Angrist, J., Oreopoulos, P., and Williams, T. (2014). When opportunity knocks, who answers? New evidence on college achievement awards. Journal of Human Resources, 49(3): $572-610$

Ariely, D. and Wertenbroch, K. (2002). Procrastination, deadlines, and performance: Selfcontrol by precommitment. Psychological Science, 13(3): 219-224

Arulampalam, W., Naylor, R.A., and Smith, J. (2012). Am I missing something? The effects of absence from class on student performance. Economics of Education Review, 31(4): $363-375$

Ashraf, N., Karlan, D., and Yin, W. (2006). Tying Odysseus to the mast: Evidence from a commitment savings product in the Philippines. Quarterly Journal of Economics, 121(2): $635-672$

Augenblick, N., Niederle, M., and Sprenger, C. (2015). Working over time: Dynamic inconsistency in real effort tasks. Quarterly Journal of Economics, 130(3): 1067-1115

Barron, K.E. and Harackiewicz, J.M. (2003). Revisiting the benefits of performanceapproach goals in the college classroom: Exploring the role of goals in advanced college courses. International Journal of Educational Research, 39(4): 357-374

Barrow, L., Richburg-Hayes, L., Rouse, C.E., and Brock, T. (2014). Paying for performance: The education impacts of a community college scholarship program for low-income adults. Journal of Labor Economics, 32(3): 563-599

Bauer, M. and Chytilová, J. (2013). Women, children and patience: Experimental evidence from Indian villages. Review of Development Economics, 17(4): 662-675

Bell, D.E. (1985). Disappointment in decision making under uncertainty. Operations Research, 33(1): 1-27

Brunnermeier, M.K. and Parker, J.A. (2005). Optimal expectations. American Economic Review, 95(4): 1092-1118

Bryan, G., Karlan, D., and Nelson, S. (2010). Commitment devices. Annual Review of Economics, 2(1): 671-698

Buechel, B., Mechtenberg, L., and Petersen, J. (2014). Peer effects and students' selfcontrol. SFB 649 Discussion Paper 2014-024, Humboldt University

Camerer, C. and Lovallo, D. (1999). Overconfidence and excess entry: An experimental approach. American Economic Review, 89(1): 306-318

Cameron, J. and Pierce, W.D. (1994). Reinforcement, reward, and intrinsic motivation: A meta-analysis. Review of Educational research, 64(3): 363-423

Castleman, B.L. (2014). The impact of partial and full merit scholarships on college entry and success: Evidence from the Florida Bright Futures Scholarship program. EdPolicyWorks Working Paper, University of Virginia

Cha, P. and Patel, R. (2010). Rewarding progress, reducing debt: Early results from Ohio's performance-based scholarship demonstration for low-income parents. Technical Report, $M D R C$ 
Chase, J.A., Houmanfar, R., Hayes, S.C., Ward, T.A., Vilardaga, J.P., and Follette, V. (2013). Values are not just goals: Online ACT-based values training adds to goal setting in improving undergraduate college student performance. Journal of Contextual Behavioral Science, 2(3): 79-84

Choi, J.J., Haisley, E., Kurkoski, J., and Massey, C. (2016). Small cues change savings choices. Mimeo, Yale University

Church, M.A., Elliot, A.J., and Gable, S.L. (2001). Perceptions of classroom environment, achievement goals, and achievement outcomes. Journal of Educational Psychology, 93(1): $43-54$

Cohodes, S.R. and Goodman, J.S. (2014). Merit aid, college quality, and college completion: Massachusetts' Adams scholarship as an in-kind subsidy. American Economic Journal: Applied Economics, 6(4): 251-285

Corgnet, B., Gómez-Miñambres, J., and Hernán-Gonzalez, R. (2015). Goal setting and monetary incentives: When large stakes are not enough. Management Science, 61(12): 2926-2944

Corgnet, B., Gómez-Miñambres, J., and Hernán-Gonzalez, R. (2016). Goal setting in the principal-agent model: Weak incentives for strong performance. CEDEX Discussion Paper 2016-09, University of Nottingham

Cornwell, C.M., Lee, K.H., and Mustard, D.B. (2005). Student responses to merit scholarship retention rules. Journal of Human Resources, 40(4): 895-917

Darnon, C., Butera, F., Mugny, G., Quiamzade, A., and Hulleman, C.S. (2009). Too complex for me! Why do performance-approach and performance-avoidance goals predict exam performance? European Journal of Psychology of Education, 24(4): 423-434

De Paola, M., Scoppa, V., and Nisticò, R. (2012). Monetary incentives and student achievement in a depressed labor market: Results from a randomized experiment. Journal of Human Capital, 6(1): 56-85

DellaVigna, S.D. and Malmendier, U. (2006). Paying not to go to the gym. American Economic Review, 96(3): 694-719

Dhami, S. (2016). The Foundations of Behavioral Economic Analysis. Oxford: Oxford University Press

Diamond, P. and Köszegi, B. (2003). Quasi-hyperbolic discounting and retirement. Journal of Public Economics, 87(9): 1839-1872

Dobkin, C., Gil, R., and Marion, J. (2010). Skipping class in college and exam performance: Evidence from a regression discontinuity classroom experiment. Economics of Education Review, 29(4): 566-575

Duckworth, A.L., Quinn, P.D., and Tsukayama, E. (2012). What No Child Left Behind leaves behind: The roles of IQ and self-control in predicting standardized achievement test scores and report card grades. Journal of Educational Psychology, 104(2): 439-451

Duckworth, A.L. and Seligman, M.E. (2005). Self-discipline outdoes IQ in predicting academic performance of adolescents. Psychological Science, 16(12): 939-944

Duckworth, A.L., Shulman, E.P., Mastronarde, A.J., Patrick, S.D., Zhang, J., and Druckman, J. (2015). Will not want: Self-control rather than motivation explains the female advantage in report card grades. Learning and Individual Differences, 39: 13-23

Dynarski, S. (2008). Building the stock of college-educated labor. Journal of Human Resources, 43(3): $576-610$

Elliot, A.J. and McGregor, H.A. (2001). A $2 \times 2$ achievement goal framework. Journal of Personality and Social Psychology, 80(3): 501-519

Fang, H. and Silverman, D. (2009). Time-inconsistency and welfare program participation: Evidence from the NLSY. International Economic Review, 50(4): 1043-1077

Firpo, S., Fortin, N.M., and Lemieux, T. (2009). Unconditional quantile regressions. Econometrica, 77(3): 953-973 
Fryer, R.G. (2011). Financial incentives and student achievement: Evidence from randomized trials. Quarterly Journal of Economics, 126(4): 1755-1798

Fryer, R.G. (2013). Information and student achievement: Evidence from a cellular phone experiment. Working Paper 19113, NBER

Genesove, D. and Mayer, C. (2001). Loss aversion and seller behavior: Evidence from the housing market. Quarterly Journal of Economics, 116(4): 1233-1260

Gill, D. and Prowse, V. (2012). A structural analysis of disappointment aversion in a real effort competition. American Economic Review, 102(1): 469-503

Gill, D. and Stone, R. (2010). Fairness and desert in tournaments. Games and Economic Behavior, 69(2): 346-364

Giné, X., Goldberg, J., Silverman, D., and Yang, D. (forthcoming). Revising commitments: Field evidence on the adjustment of prior choices. Economic Journal

Gneezy, U., Meier, S., and Rey-Biel, P. (2011). When and why incentives (don't) work to modify behavior. Journal of Economic Perspectives, 25(4): 191-209

Goerg, S.J. (2015). Goal setting and worker motivation. IZA World of Labor, 178: 1-10

Goerg, S.J. and Kube, S. (2012). Goals (th) at work-goals, monetary incentives, and workers'f performance. Preprint 2012/19, Max Planck Institute for Research on Collective Goods

Gossner, O. and Steiner, J. (2016). Optimal illusion of control and related perception biases. Discussion Paper 11478, CEPR

Griffee, D.T. and Templin, S.A. (1997). Goal setting affects task performance. In Proceedings of the JALT 1997 International Conference on Language Teaching and Learning, 21-26

Gruber, J. and Köszegi, B. (2001). Is addiction rational? Tprdicheory and evidence. Quarterly Journal of Economics, 116(4): 1261-1303

Harackiewicz, J.M., Barron, K.E., Carter, S.M., Lehto, A.T., and Elliot, A.J. (1997). Predictors and consequences of achievement goals in the college classroom: Maintaining interest and making the grade. Journal of Personality and Social Psychology, 73(6): 1284-1295

Harding, M. and Hsiaw, A. (2014). Goal setting and energy conservation. Journal of Economic Behavior \& Organization, 107: 209-227

Harrison, G.W., Lau, M.I., and Rutström, E.E. (2005). Dynamic consistency in Denmark: A longitudinal field experiment. Economics Working Paper 05-02, University of Central Florida

Heath, C., Larrick, R.P., and Wu, G. (1999). Goals as reference points. Cognitive Psychology, 38(1): 79-109

Henry, G.T., Rubenstein, R., and Bugler, D.T. (2004). Is HOPE enough? Impacts of receiving and losing merit-based financial aid. Educational Policy, 18(5): 686-709

Hsiaw, A. (2013). Goal-setting and self-control. Journal of Economic Theory, 148(2): 601-626

Hsiaw, A. (2016). Goal bracketing and self-control. Mimeo, Brandeis University

Hsieh, P., Sullivan, J.R., and Guerra, N.S. (2007). A closer look at college students: Self-efficacy and goal orientation. Journal of Advanced Academics, 18(3): 454-476

Jain, S. (2009). Self-control and optimal goals: A theoretical analysis. Marketing Science, 28(6): 1027-1045

Johnson, D.D. and Fowler, J.H. (2011). The evolution of overconfidence. Nature, 477(7364): $317-320$

Kahneman, D., Knetsch, J.L., and Thaler, R.H. (1990). Experimental tests of the endowment effect and the Coase theorem. Journal of Political Economy, 98(6): 1325-1348

Kahneman, D. and Tversky, A. (1979). Prospect theory: An analysis of decision under risk. Econometrica, 47(2): 263-291

Köszegi, B. and Rabin, M. (2006). A model of reference-dependent preferences. Quarterly Journal of Economics, 121(4): 1133-1165

Khwaja, A., Silverman, D., and Sloan, F. (2007). Time preference, time discounting, and smoking decisions. Journal of Health Economics, 26(5): 927-949 
Koch, A.K. and Nafziger, J. (2011). Self-regulation through goal setting. Scandinavian Journal of Economics, 113(1): 212-227

Koch, A.K. and Nafziger, J. (2016). Goals and bracketing under mental accounting. Journal of Economic Theory, 162: 305-351

Laibson, D. (1997). Golden eggs and hyperbolic discounting. Quarterly Journal of Economics, 112(2): 443-477

LaPorte, R.E. and Nath, R. (1976). Role of performance goals in prose learning. Journal of Educational Psychology, 68(3): 260-264

Latham, G.P. and Brown, T.C. (2006). The effect of learning vs. outcome goals on selfefficacy, satisfaction and performance in an MBA program. Applied Psychology, 55(4): 606623

Latham, G.P. and Pinder, C.C. (2005). Work motivation theory and research at the dawn of the twenty-first century. Annual Review of Psychology, 56(1): 485-516

Lavecchia, A.M., Liu, H., and Oreopoulos, P. (2016). Behavioral economics of education: Progress and possibilities. In E.A. Hanushek, S. Machin, and L. Woessman, editors, Handbook of the Economics of Education, Vol. 5, 1-74. North Holland

Leuven, E., Oosterbeek, H., and van der Klaauw, B. (2010). The effect of financial rewards on students' achievement: Evidence from a randomized experiment. Journal of the European Economic Association, 8(6): 1243-1265

Linnenbrink-Garcia, L., Tyson, D.F., and Patall, E.A. (2008). When are achievement goal orientations beneficial for academic achievement? A closer look at main effects and moderating factors. Revue Internationale de Psychologie Sociale, 21(1): 19-70

Locke, E.A. (1968). Toward a theory of task motivation and incentives. Organizational Behavior and Human Performance, 3(2): 157-189

Locke, E.A. and Latham, G.P. (2002). Building a practically useful theory of goal setting and task motivation: A 35-year odyssey. American Psychologist, 57(9): 705-717

Locke, E.A., Shaw, K.N., Saari, L.M., and Latham, G.P. (1981). Goal setting and task performance: 1969-1980. Psychological Bulletin, 90(1): 125-152

McLeish, K.N. and Oxoby, R.J. (2007). Gender, affect and intertemporal consistency: An experimental approach. Discussion Paper 2663, IZA

Meier, S. and Sprenger, C. (2010). Present-biased preferences and credit card borrowing. American Economic Journal: Applied Economics, 2(1): 193-210

Mento, A.J., Steel, R.P., and Karren, R.J. (1987). A meta-analytic study of the effects of goal setting on task performance: 1966-1984. Organizational Behavior and Human Decision Processes, 39(1): 52-83

Miller, C., Binder, M., Harris, V., and Krause, K. (2011). Staying on track: Early findings from a performance-based scholarship program at the university of New Mexico. Technical Report, $M D R C$

Morgan, M. (1987). Self-monitoring and goal setting in private study. Contemporary Educational Psychology, 12(1): 1-6

Morisano, D., Hirsh, J.B., Peterson, J.B., Pihl, R.O., and Shore, B.M. (2010). Setting, elaborating, and reflecting on personal goals improves academic performance. Journal of Applied Psychology, 95(2): 255-264

Park, Y.J. and Santos-Pinto, L. (2010). Overconfidence in tournaments: Evidence from the field. Theory and Decision, 69(1): 143-166

Patel, R. and Rudd, T. (2012). Can scholarships alone help students succeed? Lessons from two New York City community colleges. Technical Report, MDRC

Patterson, R.W. (2016). Can behavioral tools improve online student outcomes? Experimental evidence from a massive open online course. Mimeo, United States Military Academy at West Point

Pollak, R.A. (1968). Consistent planning. Review of Economic Studies, 35(2): 201-208 
Prince, J.T. and Shawhan, D.L. (2011). Is time inconsistency primarily a male problem? Applied Economics Letters, 18(6): 501-504

Rabin, M. (2000). Risk aversion and expected-utility theory: A calibration theorem. Econometrica, 68(5): 1281-1292

Romer, D. (1993). Do students go to class? Should they? Journal of Economic Perspectives, 7(3): 167-174

Schunk, D.H. (1983). Developing children's self-efficacy and skills: The roles of social comparative information and goal setting. Contemporary Educational Psychology, 8(1): 76-86

Schunk, D.H. (1984). Enhancing self-efficacy and achievement through rewards and goals: Motivational and informational effects. Journal of Educational Research, 78(1): 29-34

Schunk, D.H. (1996). Goal and self-evaluative influences during children's cognitive skill learning. American Educational Research Journal, 33(2): 359-382

Schunk, D.H. and Ertmer, P.A. (1999). Self-regulatory processes during computer skill acquisition: Goal and self-evaluative influences. Journal of Educational Psychology, 91(2): $251-260$

Schunk, D.H. and Rice, J.M. (1991). Learning goals and progress feedback during reading comprehension instruction. Journal of Literacy Research, 23(3): 351-364

Schunk, D.H. and Swartz, C.W. (1993). Goals and progress feedback: Effects on self-efficacy and writing achievement. Contemporary Educational Psychology, 18(3): 337-354

Schutz, P.A. and Lanehart, S.L. (1994). Long-term educational goals, subgoals, learning strategies use and the academic performance of college students. Learning and Individual Differences, 6(4): 399-412

Scott-Clayton, J. (2011). On money and motivation: A quasi-experimental analysis of financial incentives for college achievement. Journal of Human Resources, 46(3): 614-646

Scrivener, S., Weiss, M.J., Ratledge, A., Rudd, T., Sommo, C., and Fresques, H. (2015). Doubling graduation rates: Three-year effects of CUNY's Accelerated Study in Associate Programs (ASAP) for developmental education students. Technical Report, MDRC

Shih, S.S. and Alexander, J.M. (2000). Interacting effects of goal setting and self- or otherreferenced feedback on children's development of self-efficacy and cognitive skill within the Taiwanese classroom. Journal of Educational Psychology, 92(3): 536-543

Smithers, S. (2015). Goals, motivation and gender. Economics Letters, 131: 75-77

Strotz, R.H. (1956). Myopia and inconsistency in dynamic utility maximization. Review of Economic Studies, 23(3): 165-180

Suvorov, A. and Van de Ven, J. (2008). Goal setting as a self-regulation mechanism. Working Paper 122, CEFIR NES

Tanaka, T., Camerer, C.F., and Nguyen, Q. (2010). Risk and time preferences: Linking experimental and household survey data from Vietnam. American Economic Review, 100(1): $557-571$

Thaler, R.H. and Benartzi, S. (2004). Save more tomorrow ${ }^{T M}$ : Using behavioral economics to increase employee saving. Journal of Political Economy, 112(S1): S164-S187

Weinstein, N.D. (1980). Unrealistic optimism about future life events. Journal of Personality and Social Psychology, 39(5): 806-820

Wertenbroch, K. (1998). Consumption self-control by rationing purchase quantities of virtue and vice. Marketing Science, 17(4): 317-337

Wu, G., Heath, C., and Larrick, R. (2008). A prospect theory model of goal behavior. Mimeo, University of Chicago

Zimmerman, B.J. and Bandura, A. (1994). Impact of self-regulatory influences on writing course attainment. American Educational Research Journal, 31(4): 845-862 


\section{Supplementary Web Appendix}

(Intended for Online Publication) 


\section{Supplementary Web Appendix I Tables}

\begin{tabular}{|c|c|c|c|c|c|}
\hline & \multicolumn{2}{|c|}{ Mean value } & \multicolumn{3}{|c|}{ Treatment-Control difference } \\
\hline & Treatment group & Control group & Difference & S.E. & $p$-value \\
\hline Age & 0.005 & -0.005 & 0.010 & 0.032 & 0.764 \\
\hline Male & 0.477 & 0.455 & 0.022 & 0.016 & 0.171 \\
\hline Black & 0.064 & 0.051 & 0.012 & 0.007 & 0.091 \\
\hline Non-Hispanic white & 0.604 & 0.619 & -0.015 & 0.015 & 0.328 \\
\hline Hispanic & 0.193 & 0.192 & 0.000 & 0.013 & 0.984 \\
\hline Asian & 0.102 & 0.092 & 0.009 & 0.009 & 0.328 \\
\hline SAT score & 0.001 & -0.001 & 0.002 & 0.032 & 0.945 \\
\hline High school GPA & -0.016 & 0.016 & -0.032 & 0.032 & 0.320 \\
\hline Advanced placement credit & 0.759 & 0.756 & 0.003 & 0.014 & 0.800 \\
\hline Fall semester & 0.620 & 0.607 & 0.012 & 0.015 & 0.435 \\
\hline First login time & -0.004 & 0.004 & -0.007 & 0.032 & 0.820 \\
\hline
\end{tabular}

Notes: The Treatment and Control groups contain 1,979 and 1,992 students respectively. Information about age, gender, race, SAT scores, high school GPA and advanced placement credit was obtained from the university's Registrar data. Age is measured on the first of the month in which the semester began and is rounded down to the nearest whole month. The variable SAT score is the sum of the student's scores on the verbal, analytic and numerical components of the primary aptitude test in the Registrar data (these are SAT scores for the majority of students). Advanced placement credit is an indicator for the student having entered the university with advanced placement credit. Fall semester is an indicator for the student having participated in the course in the Fall semester. First login time is the elapsed time between when the first email invitation to take the syllabus quiz was sent and when the student first logged into the course webpage. Each of the non-binary characteristics (age, SAT score, high School GPA and first login time) has been standardized to have a mean of zero and a variance of one within the Fall 2013 and Spring 2014 semesters combined (the performance-based goals experiment) and within the Fall 2014 and Spring 2015 semesters combined (the task-based goals experiment). The standardization of SAT score is stratified to ensure that this variable has the same mean and the same variance among students taking each type of aptitude test. S.E. is the standard error of the difference between the characteristic mean in the Treatment group and the characteristic mean in the Control group and is obtained assuming independent samples with equal variances. $p$-value is the two-sided $p$-value for the null hypothesis that the magnitude of the difference between the characteristic mean in the Treatment group and the characteristic mean in the Control group is zero. The joint significance of the characteristics is tested using a $\chi$-squared test based on the results of a probit regression of an indicator for treatment on an intercept and the eleven characteristics listed in this table: the $p$-value for the joint null hypothesis that none of the eleven characteristics predicts treatment is 0.636.

Table SWA.1: Characteristics of students across all semesters 


\begin{tabular}{|c|c|c|c|c|c|}
\hline & \multicolumn{2}{|c|}{ Mean value } & \multicolumn{3}{|c|}{ Treatment-Control difference } \\
\hline & Treatment group & Control group & Difference & S.E. & $p$-value \\
\hline Age & 0.007 & -0.007 & 0.014 & 0.045 & 0.761 \\
\hline Male & 0.491 & 0.457 & 0.035 & 0.023 & 0.124 \\
\hline Black & 0.069 & 0.047 & 0.022 & 0.011 & 0.037 \\
\hline Non-Hispanic white & 0.628 & 0.644 & -0.016 & 0.022 & 0.464 \\
\hline Hispanic & 0.175 & 0.175 & 0.000 & 0.017 & 0.999 \\
\hline Asian & 0.094 & 0.085 & 0.009 & 0.013 & 0.482 \\
\hline SAT score & -0.048 & 0.050 & -0.098 & 0.045 & 0.030 \\
\hline High school GPA & -0.044 & 0.045 & -0.089 & 0.045 & 0.049 \\
\hline Advanced placement credit & 0.762 & 0.770 & -0.008 & 0.019 & 0.686 \\
\hline Fall semester & 0.575 & 0.591 & -0.016 & 0.022 & 0.482 \\
\hline First login time & -0.003 & 0.004 & -0.007 & 0.045 & 0.876 \\
\hline
\end{tabular}

Notes: The Treatment and Control groups contain 995 and 972 students respectively. The $p$-value for the joint null hypothesis that none of the eleven characteristics predicts treatment is 0.153. Also see the notes to Table SWA.1.

Table SWA.2: Characteristics of students in Fall 2013 \& Spring 2014 semesters (performance-based goals experiment)

\begin{tabular}{|c|c|c|c|c|c|}
\hline & \multicolumn{2}{|c|}{ Mean value } & \multicolumn{3}{|c|}{ Treatment-Control difference } \\
\hline & Treatment group & Control group & Difference & S.E. & $p$-value \\
\hline Age & 0.003 & -0.003 & 0.005 & 0.045 & 0.903 \\
\hline Male & 0.462 & 0.454 & 0.008 & 0.022 & 0.704 \\
\hline Black & 0.058 & 0.055 & 0.003 & 0.010 & 0.769 \\
\hline Non-Hispanic white & 0.579 & 0.595 & -0.016 & 0.022 & 0.472 \\
\hline Hispanic & 0.210 & 0.209 & 0.002 & 0.018 & 0.932 \\
\hline Asian & 0.109 & 0.099 & 0.010 & 0.014 & 0.476 \\
\hline SAT score & 0.051 & -0.049 & 0.101 & 0.045 & 0.024 \\
\hline High school GPA & 0.013 & -0.012 & 0.025 & 0.045 & 0.579 \\
\hline Advanced placement credit & 0.756 & 0.742 & 0.014 & 0.019 & 0.472 \\
\hline Fall semester & 0.665 & 0.624 & 0.041 & 0.021 & 0.055 \\
\hline First login time & -0.004 & 0.004 & -0.007 & 0.045 & 0.868 \\
\hline
\end{tabular}

Notes: The Treatment and Control groups contain 984 and 1,020 students respectively. The $p$-value for the joint null hypothesis that none of the eleven characteristics predicts treatment is 0.471 . Also see the notes to Table SWA.1.

Table SWA.3: Characteristics of students in Fall 2014 \& Spring 2015 semesters (task-based goals experiment) 
Panel I: All students in the task-based goals experiment

\begin{tabular}{|c|c|c|c|c|}
\hline & \multicolumn{2}{|c|}{ Total points score } & \multirow{2}{*}{$\frac{\operatorname{Pr}(\text { Grade } \geq A-)}{\text { OLS }}$} & \multirow{2}{*}{$\begin{array}{c}\operatorname{Pr}(\text { Grade } \geq \mathrm{B}+) \\
\text { OLS }\end{array}$} \\
\hline & OLS & Median & & \\
\hline $\begin{array}{l}\text { Effect of asking students to set } \\
\text { task-based goals }\end{array}$ & $\begin{array}{c}0.743 \\
(0.474) \\
{[0.117]}\end{array}$ & $\begin{array}{l}0.924^{*} \\
(0.475) \\
{[0.052]}\end{array}$ & $\begin{array}{l}0.042^{*} \\
(0.022) \\
{[0.057]}\end{array}$ & $\begin{array}{c}0.043^{*} \\
(0.022) \\
{[0.052]}\end{array}$ \\
\hline Effect / (SD in Control group) & 0.068 & 0.085 & 0.086 & 0.087 \\
\hline Mean of dependent variable in Control group & 83.111 & 83.111 & 0.393 & 0.493 \\
\hline Observations & 2,004 & 2,004 & 2,004 & 2,004 \\
\hline
\end{tabular}

Panel II: Male students in the task-based goals experiment

\begin{tabular}{|c|c|c|c|c|}
\hline & \multicolumn{2}{|c|}{ Total points score } & \multirow{2}{*}{$\frac{\operatorname{Pr}\left(\text { Grade } \geq \mathrm{A}^{-}\right)}{\text {OLS }}$} & \multirow{2}{*}{$\frac{\operatorname{Pr}(\text { Grade } \geq \mathrm{B}+)}{\text { OLS }}$} \\
\hline & OLS & Median & & \\
\hline $\begin{array}{l}\text { Effect of asking students to set } \\
\text { task-based goals }\end{array}$ & $\begin{array}{l}1.581^{* *} \\
(0.706) \\
{[0.025]}\end{array}$ & $\begin{array}{l}1.700^{* *} \\
(0.674) \\
{[0.012]}\end{array}$ & $\begin{array}{l}0.093^{* * *} \\
(0.033) \\
{[0.005]}\end{array}$ & $\begin{array}{l}0.058^{*} \\
(0.033) \\
{[0.078]}\end{array}$ \\
\hline Effect / (SD in Control group) & 0.141 & 0.151 & 0.189 & 0.115 \\
\hline Mean of dependent variable in Control group & 83.285 & 83.285 & 0.417 & 0.529 \\
\hline Observations & 918 & 918 & 918 & 918 \\
\hline
\end{tabular}

Panel III: Female students in the task-based goals experiment

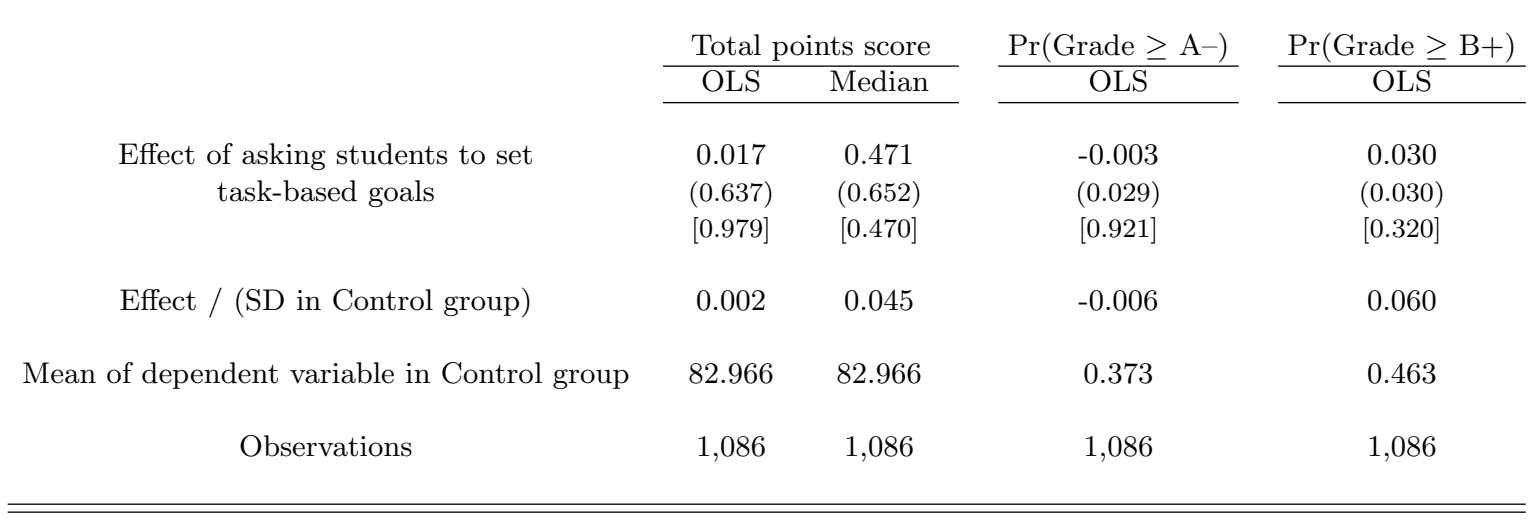

Notes: The regressions are the same as those reported in Table 5, except that we no longer include controls for student characteristics. Heteroskedasticity-consistent standard errors are shown in round brackets and two-sided $p$-values are shown in square brackets. ${ }^{*},{ }^{* *}$ and ${ }^{* * *}$ denote, respectively, significance at the $10 \%, 5 \%$ and $1 \%$ levels (two-sided tests).

Table SWA.4: Effects of task-based goals on student performance without controls for student characteristics 
Panel I: All students in the performance-based goals experiment

\begin{tabular}{ccccc} 
Effect of asking students to set & -0.237 & -0.360 & -0.020 & -0.022 \\
performance-based goals & $(0.458)$ & $(0.494)$ & $(0.022)$ & $(0.023)$ \\
& {$[0.605]$} & {$[0.466]$} & {$[0.360]$} & -0.043 \\
Effect / (SD in Control group) & -0.022 & -0.034 & -0.041 & 0.498 \\
Mean of dependent variable in Control group & 83.220 & 83.220 & 0.389 & 1,967 \\
Observations & 1,967 & 1,967 & 1,967 & \\
\hline
\end{tabular}

Panel II: Male students in the performance-based goals experiment

\begin{tabular}{|c|c|c|c|c|}
\hline & \multicolumn{2}{|c|}{ Total points score } & \multirow{2}{*}{$\frac{\operatorname{Pr}\left(\text { Grade } \geq \mathrm{A}^{-}\right)}{\text {OLS }}$} & \multirow{2}{*}{$\frac{\operatorname{Pr}(\text { Grade } \geq B+)}{\text { OLS }}$} \\
\hline & OLS & Median & & \\
\hline \multirow{3}{*}{$\begin{array}{l}\text { Effect of asking students to set } \\
\text { performance-based goals }\end{array}$} & -0.223 & 0.041 & -0.015 & 0.002 \\
\hline & $(0.672)$ & $(0.665)$ & $(0.032)$ & $(0.033)$ \\
\hline & {$[0.740]$} & {$[0.951]$} & {$[0.649]$} & {$[0.951]$} \\
\hline Effect / (SD in Control group) & -0.021 & 0.004 & -0.030 & 0.004 \\
\hline Mean of dependent variable in Control group & 83.644 & 83.644 & 0.403 & 0.511 \\
\hline Observations & 933 & 933 & 933 & 933 \\
\hline
\end{tabular}

Panel III: Female students in the performance-based goals experiment

\begin{tabular}{|c|c|c|c|c|}
\hline & \multicolumn{2}{|c|}{ Total points score } & \multirow{2}{*}{$\frac{\operatorname{Pr}\left(\text { Grade } \geq \mathrm{A}^{-}\right)}{\text {OLS }}$} & \multirow{2}{*}{$\frac{\operatorname{Pr}(\text { Grade } \geq B+)}{\text { OLS }}$} \\
\hline & OLS & Median & & \\
\hline $\begin{array}{l}\text { Effect of asking students to set } \\
\text { performance-based goals }\end{array}$ & $\begin{array}{c}-0.304 \\
(0.625) \\
{[0.626]}\end{array}$ & $\begin{array}{c}-0.810 \\
(0.689) \\
{[0.240]}\end{array}$ & $\begin{array}{c}-0.027 \\
(0.030) \\
{[0.365]}\end{array}$ & $\begin{array}{c}-0.046 \\
(0.031) \\
{[0.138]}\end{array}$ \\
\hline Effect / (SD in Control group) & -0.029 & -0.076 & -0.056 & -0.092 \\
\hline Mean of dependent variable in Control group & 82.864 & 82.864 & 0.377 & 0.487 \\
\hline Observations & 1,034 & 1,034 & 1,034 & 1,034 \\
\hline
\end{tabular}

Notes: The regressions are the same as those reported in Table 7, except that we no longer include controls for student characteristics. Heteroskedasticity-consistent standard errors are shown in round brackets and two-sided $p$-values are shown in square brackets. ${ }^{*},{ }^{* *}$ and ${ }^{* * *}$ denote, respectively, significance at the $10 \%, 5 \%$ and $1 \%$ levels (two-sided tests).

Table SWA.5: Effects of performance-based goals on student performance without controls for student characteristics 


\section{Supplementary Web Appendix II Figures}

\begin{tabular}{|c|c|c|c|}
\hline Component & Points available & Points scored & Answer key \\
\hline Syllabus Quiz & 2 & 2 & N/A \\
\hline Start-Of-Course Survey & 2 & 2 & N/A \\
\hline Quiz 1 & 3 & 2 & Answer Key \\
\hline Quiz 2 & 3 & 3 & Answer Key \\
\hline Quiz 3 & 3 & 2 & Answer Key \\
\hline Quiz 4 & 3 & 2 & Answer Key \\
\hline Quiz 5 & 3 & & \\
\hline Quiz 6 & 3 & & \\
\hline Quiz 7 & 3 & & \\
\hline Quiz 8 & 3 & & \\
\hline Quiz 9 & 3 & & \\
\hline Quiz 10 & 3 & & \\
\hline & & & \\
\hline Best Midterm & 30 & & \\
\hline Midterm 1 & & & \\
\hline Midterm 2 & & & \\
\hline & & & \\
\hline Final Exam & 34 & & \\
\hline & & & \\
\hline End-Of-Course-Survey & 2 & & \\
\hline & & & \\
\hline Total Points & $\mathbf{1 0 0}$ & & \\
\hline
\end{tabular}

Grade Key

\begin{tabular}{|c|c|}
\hline Total Points Scored (out of 100) & Letter Grade \\
\hline 91 and above & A \\
\hline 90 to 88 & A- \\
\hline 87 to 86 & B+ \\
\hline 85 to 81 & B \\
\hline 80 to 78 & B- \\
\hline 77 to 76 & C+ \\
\hline 75 to 70 & C \\
\hline 69 to 66 & D \\
\hline 65 and below & E \\
\hline
\end{tabular}

Figure SWA.1: Example gradecard for a student in the Control group (Fall 2013 semester) 


\section{Consent Form for Cornell University Research Team Study on Course Performance}

Before you start the survey, I want to tell you about a "Cornell University Research Team" that is conducting research to evaluate which factors contribute to good performance on this course.

Research Method

The team will use:

- Survey responses.

- Grades from this course.

- Information held by the [University name] registrar (e.g., admissions data, demographic information).

Confidentiality

- All the information will be made anonymous.

- This means that your name will never be seen by the Cornell University Research Team and will not be associated with the findings.

What you will be asked to do in this study

Nothing.

$\underline{\text { Risks }}$

There are no risks to you.

Right to withdraw from the study

You have the right to withdraw from the study at any time during the semester. If you withdraw there will be no consequences for you; your academic standing, record, or relationship with the university will not be affected. Details of how to withdraw are available from the course webpage.

Who to contact if you have questions about the study:

Cornell Research Team: [curt@cornell.edu]

Full contact details are available from the course webpage.

Who to contact about your rights as a participant in this study:

Cornell Institutional Review Board, Ithaca NY. Email: irbhp@cornell.edu, phone: 607-255-5138; website: www.irb.cornell.edu. Concerns/complaints can also be anonymously reported through Ethicspoint (web: www.hotline.cornell.edu, phone (toll-free): 1-866-293-3077). Full contact details are available from the course webpage.

The Cornell University Research Team would be very grateful if you'd be willing to consent to your data being used in this study. Remember that your name will never be seen by the Research Team and there is nothing you need to do. (If you choose not to consent, you will still receive [1\%][2\%] towards your score for this course from completing the survey).

$$
\text { Yes, I consent }
$$

$$
\text { No, I don't consent }
$$

Figure SWA.2: Consent form 
Please set a goal for your grade in this course.

Think carefully before setting your goal.

The professor and the TA will not see your goal. However, each time you get your quiz, midterm and final scores back, your gradecard will remind you of your goal.

\section{My goal for this course is:}

$$
\begin{array}{ll}
\odot & \mathrm{A} \\
\odot & \mathrm{A}- \\
\odot & \mathrm{B}+ \\
\odot & \mathrm{B} \\
\odot & \mathrm{B}- \\
\odot & \mathrm{C}+ \\
\odot & \mathrm{C} \\
\odot & \mathrm{D} \\
\odot & \mathrm{E} \\
\odot & \text { Prefer not to say }
\end{array}
$$

Figure SWA.3: Fall 2013 semester goal-setting question in start-of-course survey

Please set a goal for your score in the [Midterm 1][Midterm 2][Final] Exam.

Think carefully before setting your goal.

The professor and the TA will not see your goal. However, each time you get your quiz, midterm and final exam scores back, your gradecard will remind you of your goal.

My goal for my score in the [Midterm 1][Midterm 2][Final] Exam is:

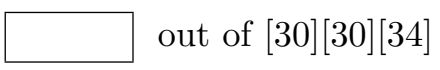

$\odot$ Prefer not to say

Figure SWA.4: Spring 2014 semester goal-setting question in mid-course surveys 


\section{The goal that you set for this course is: $\mathrm{X}$}

(You set your goal in the start-of-course survey)

\begin{tabular}{|c|c|c|c|}
\hline Component & Points available & Points scored & Answer key \\
\hline Syllabus Quiz & 2 & 2 & N/A \\
\hline Start-Of-Course Survey & 2 & 2 & N/A \\
\hline Quiz 1 & 3 & 2 & Answer Key \\
\hline Quiz 2 & 3 & 3 & $\underline{\text { Answer Key }}$ \\
\hline Quiz 3 & 3 & 2 & Answer Key \\
\hline$\ldots$ & $\ldots$ & $\ldots$ & $\ldots$ \\
\hline
\end{tabular}

Figure SWA.5: Fall 2013 semester goal reminder on gradecard

\begin{tabular}{|c|c|c|c|}
\hline Component & Points available & Points scored & Answer key \\
\hline$\ldots$ & $\ldots$ & $\ldots$ & $\ldots$ \\
$\ldots$ & $\ldots$ & $\ldots$ & $\ldots$ \\
$\ldots$ & $\ldots$ & $\ldots$ & $\ldots$ \\
\hline Best Midterm & 30 & 24 & \\
\hline Midterm 1 & & 22 & Your goal $(*): \mathbf{X}$ \\
\hline Midterm 2 & & 24 & Your goal $(*): \mathbf{Y}$ \\
\hline & & & \\
\hline Final Exam & 34 & & Your goal (*): Z \\
\hline & & & \\
\hline End-Of-Course-Survey & 1 & & \\
\hline & & & \\
\hline Total Points & $\mathbf{1 0 0}$ & $\mathbf{4 1}$ & \\
\hline
\end{tabular}

* You set this goal as part of a Mid-Course Survey

Grade Key

\begin{tabular}{|c|c|}
\hline Total Points Scored (out of 100) & Letter Grade \\
\hline 91 and above & A \\
\hline$\cdots$ & $\cdots$ \\
\hline
\end{tabular}

Figure SWA.6: Spring 2014 semester goal reminder on gradecard 


\section{\{TREATED AND CONTROL STUDENTS $\}$}

Practice Exams

There will be 5 practice exams for the [Midterm 1][Midterm 2][Final] Exam. Each practice exam will contain the same number of questions as the [Midterm 1][Midterm 2][Final] Exam.

The practice exams for the [Midterm 1][Midterm 2][Final] Exam will become active when Mid-Course Survey [1][2][3] closes. You will receive a reminder email at that time.

\section{\{TREATED STUDENTS ONLY\}}

Question 6

Please set a goal for the number of practice exams that you will complete out of the 5 practice exams for the [Midterm 1][Midterm 2][Final] Exam.

Think carefully before setting your goal.

The professor and the TA will not see your goal. However, when you take the practice exams you will be reminded of your goal.

My goal is to complete

$\square$ out of the 5 practice exams for the [Midterm 1][Midterm 2][Final] Exam $\odot$ Prefer not to say

Figure SWA.7: Fall 2014 \& Spring 2015 semesters practice exams information and goal-setting question in mid-course surveys 
Dear Econ2023 Students,

The 5 practice exams for the [Midterm 1][Midterm 2][Final] Exam are now active.

\{TReated StUdents only Y Your goal is to complete X out of the 5 practice exams (you set this goal as part of Mid-Course Survey [1][2][3]).

To go to the practice exams, please go to the course webpage and follow the link.

Note that you will not receive any further reminders about the practice exams for the [Midterm 1][Midterm 2][Final] Exam and the practice exams will close when the [Midterm 1][Midterm 2][Final] Exam begins.

This is an automated email from the ECO 2023 system.

Figure SWA.8: Fall 2014 \& Spring 2015 semesters practice exams reminder email

Practice Exams for the [Midterm 1][Midterm 2][Final] Exam

You have completed X out of the 5 practice exams for the [Midterm 1][Midterm 2][Final] Exam

\{TReated students only Y Your goal is to complete $\mathbf{Z}$ out of the $\mathbf{5}$ practice exams (you set this goal as part of Mid-course Survey [1][2][3]).

Instructions:

- To take one of the practice exams, click on the link below.

- You can only take each practice exam once.

- There is no time limit.

- After answering each question, you will be given the correct answer.

- This will be your only opportunity to see the correct answer.

- You will not be able to go back to previous questions.

Practice Exam X+1

Figure SWA.9: Fall 2014 \& Spring 2015 semesters practice exams introductory screen 
Practice Exam X for the [Midterm 1][Midterm 2][Final] Exam Your score was $\mathbf{Y}$ out of [30][30][34]

You have now completed $\mathrm{X}$ out of the 5 practice exams for the [Midterm 1][Midterm 2][Final] Exam

\{TReated Students only Your goal is to complete $\mathbf{Z}$ out of the $\mathbf{5}$ practice exams (you set this goal as part of Mid-course Survey [1][2][3]).

Return To Practice Exams Screen

Figure SWA.10: Fall 2014 \& Spring 2015 semesters practice exams feedback screen 


\section{Supplementary Web Appendix III Formal results and proofs}

\section{Supplementary Web Appendix III.1 Proofs for Section 5.2.1}

\section{Proof of Remark 1.}

In the absence of a goal, the student-actor's utility and the student-planner's utility are given by, respectively:

$$
\begin{aligned}
u_{a c t}(e) & =\beta \delta f(e)-C(e) \\
& =\beta \delta e-\frac{c e^{2}}{2} ; \\
u_{p l a n}(e) & =\beta \delta^{2} f(e)-\beta \delta C(e) \\
& =\beta \delta^{2} e-\beta \delta \frac{c e^{2}}{2} .
\end{aligned}
$$

Both utilities are strictly concave since $c>0$. Straightforward maximization then gives the result.

\section{Proof of Proposition 1.}

Using (2), on the range $e \in[0, g]$ :

$$
\begin{aligned}
\frac{\partial u_{a c t}}{\partial e} & =\beta \delta(1+l)-c e ; \\
\frac{\partial^{2} u_{a c t}}{\partial e^{2}} & =-c<0 ; \text { and so } \\
e^{*} & =\min \{\bar{e}, g\} .
\end{aligned}
$$

Using (2), on the range $e \in[g, \infty)$ :

$$
\begin{aligned}
\frac{\partial u_{a c t}}{\partial e} & =\beta \delta-c e ; \\
\frac{\partial^{2} u_{a c t}}{\partial e^{2}} & =-c<0 ; \quad \text { and so } \\
e^{*} & =\max \{\underline{e}, g\} .
\end{aligned}
$$

(i) When $g \leq \underline{e}$, on the range $e \in[0, g], e^{*}=g$, and on the range $e \in[g, \infty), e^{*}=\underline{e}$. Thus, on the range $e \in[0, \infty), e^{*}=\underline{e}$.

(ii) When $g \in[\underline{e}, \bar{e}]$, on the range $e \in[0, g], e^{*}=g$, and on the range $e \in[g, \infty), e^{*}=g$. Thus, on the range $e \in[0, \infty), e^{*}=g$.

(iii) When $g \geq \bar{e}$, on the range $e \in[0, g], e^{*}=\bar{e}$, and on the range $e \in[g, \infty), e^{*}=g$. Thus, on the range $e \in[0, \infty), e^{*}=\bar{e}$.

\section{Proof of Proposition 2.}

On the range $g \in[0, \underline{e}], e^{*}(g)=\underline{e}$ from Proposition 1 , and so $\partial e^{*} / \partial g=0$ and $\max \left\{g-e^{*}(g), 0\right\}=0$. Using (4), $d u_{\text {plan }} / d g=0$ and so any $g \in[0, \underline{e}]$ is optimal (including $\underline{e}$ ).

On the range $g \in[\underline{e}, \bar{e}], e^{*}(g)=g$ from Proposition 1 , and so $\partial e^{*} / \partial g=1$ and 
$\max \left\{g-e^{*}(g), 0\right\}=0$. Using (4), and noting that $\hat{e}>\underline{e}$ and $\bar{e}>\underline{e}$ :

$$
\begin{aligned}
\frac{d u_{\text {plan }}}{d g} & =\beta \delta^{2}-\beta \delta c g \\
\frac{d^{2} u_{p l a n}}{d g^{2}} & =-\beta \delta c<0 ; \text { and so } \\
g^{*} & =\min \{\hat{e}, \bar{e}\}>\underline{e} .
\end{aligned}
$$

On the range $g \in[\bar{e}, \infty), e^{*}(g)=\bar{e}$ from Proposition 1 , and so $\partial e^{*} / \partial g=0$ and $\max \left\{g-e^{*}(g), 0\right\}=g-\bar{e}$. Using $(4), d u_{p l a n} / d g=-\beta \delta^{2} l<0$ and so $g^{*}=\bar{e}$.

Stitching the ranges together gives $g^{*}=\min \{\hat{e}, \bar{e}\}>\underline{e}$. Parts (ii) and (iii) follow, given that $\bar{e}<\hat{e} \Leftrightarrow \beta(1+l)<1$. Finally, (iv) follows immediately from Proposition 1 . 


\section{Supplementary Web Appendix III.2 Results and proofs for Section 5.3.1}

\section{Remark SWA.1}

In the absence of a goal the student exhibits time inconsistency:

(i) The student-actor chooses a level of task completion $\underline{a}=\beta \delta \theta / \kappa$.

(ii) The student-planner would like the student-actor to choose a level of task completion $\hat{a}=$ $\delta \theta / \kappa>\underline{a}$.

\section{Proof of Remark SWA.1.}

In the absence of a goal, the student-actor's utility and the student-planner's utility are given by, respectively:

$$
\begin{aligned}
u_{a c t}(a) & =\beta \delta f(a)-C(a) \\
& =\beta \delta \theta a-\frac{\kappa a^{2}}{2} ; \\
u_{\text {plan }}(a) & =\beta \delta^{2} f(a)-\beta \delta C(a) \\
& =\beta \delta^{2} \theta a-\beta \delta \frac{\kappa a^{2}}{2} .
\end{aligned}
$$

Both utilities are strictly concave since $\kappa>0$. Straightforward maximization then gives the result.

\section{Proposition SWA.1}

Let $\bar{a}=(\beta \delta \theta+\lambda) / \kappa$ and recall from Remark $S W A .1$ that $\underline{a}=\beta \delta \theta / \kappa<\bar{a}$ denotes the studentactor's level of task completion in the absence of a goal.

(i) When $g \leq \underline{a}$, the student-actor chooses a level of task completion $a^{*}=\underline{a}$.

(ii) When $g \in[\underline{a}, \bar{a}]$, the student-actor chooses a level of task completion $a^{*}=g$.

(iii) When $g \geq \bar{a}$, the student-actor chooses a level of task completion $a^{*}=\bar{a}$.

\section{Proof of Proposition SWA.1.}

Using (6), on the range $a \in[0, g]$ :

$$
\begin{aligned}
\frac{\partial u_{a c t}}{\partial a} & =\beta \delta \theta+\lambda-\kappa a ; \\
\frac{\partial^{2} u_{a c t}}{\partial a^{2}} & =-\kappa<0 ; \quad \text { and so } \\
a^{*} & =\min \{\bar{a}, g\} .
\end{aligned}
$$

Using (6), on the range $a \in[g, \infty)$ :

$$
\begin{aligned}
\frac{\partial u_{a c t}}{\partial a} & =\beta \delta \theta-\kappa a ; \\
\frac{\partial^{2} u_{a c t}}{\partial a^{2}} & =-\kappa<0 ; \text { and so } \\
a^{*} & =\max \{\underline{a}, g\} .
\end{aligned}
$$

(i) When $g \leq \underline{a}$, on the range $a \in[0, g], a^{*}=g$, and on the range $a \in[g, \infty), a^{*}=\underline{a}$. Thus, on the range $a \in[0, \infty), a^{*}=\underline{a}$. 
(ii) When $g \in[\underline{a}, \bar{a}]$, on the range $a \in[0, g], a^{*}=g$, and on the range $a \in[g, \infty), a^{*}=g$. Thus, on the range $a \in[0, \infty), a^{*}=g$.

(iii) When $g \geq \bar{a}$, on the range $a \in[0, g], a^{*}=\bar{a}$, and on the range $a \in[g, \infty), a^{*}=g$. Thus, on the range $a \in[0, \infty), a^{*}=\bar{a}$.

\section{Proposition SWA.2}

Recall from Remark SWA.1 that $\underline{a}=\beta \delta \theta / \kappa$ and $\hat{a}=\delta \theta / \kappa$ denote, respectively, student-actor task completion and student-planner desired task completion in the absence of a goal.

Recall from Proposition $S W A .1$ that $\bar{a}=(\beta \delta \theta+\lambda) / \kappa$ denotes maximal student-actor task completion in the presence of a goal.

(i) The optimal choice of goal for the student-planner is given by $g^{*}=\min \{\hat{a}, \bar{a}\}$.

(ii) When $\beta \delta \theta+\lambda<\delta \theta, g^{*}=\bar{a}$.

(iii) When $\beta \delta \theta+\lambda \geq \delta \theta, g^{*}=\hat{a}$.

(iv) Student-actor task completion $a^{*}=g^{*}>\underline{a}$, and so the level of task completion is higher than in the absence of goal.

\section{Proof of Proposition SWA.2.}

On the range $g \in[0, \underline{a}], a^{*}(g)=\underline{a}$ from Proposition SWA.1, and so $\partial a^{*} / \partial g=0$ and $\max \left\{g-a^{*}(g), 0\right\}=0$. Using (8), $d u_{\text {plan }} / d g=0$ and so any $g \in[0, \underline{a}]$ is optimal (including $\underline{a}$ ).

On the range $g \in[\underline{a}, \bar{a}], a^{*}(g)=g$ from Proposition SWA.1, and so $\partial a^{*} / \partial g=1$ and $\max \left\{g-a^{*}(g), 0\right\}=0$. Using (8), and noting that $\hat{a}>\underline{a}$ and $\bar{a}>\underline{a}$ :

$$
\begin{aligned}
\frac{d u_{\text {plan }}}{d g} & =\beta \delta^{2} \theta-\beta \delta \kappa g \\
\frac{d^{2} u_{\text {plan }}}{d g^{2}} & =-\beta \delta \kappa<0 ; \text { and so } \\
g^{*} & =\min \{\hat{a}, \bar{a}\}>\underline{a} .
\end{aligned}
$$

On the range $g \in[\bar{a}, \infty), a^{*}(g)=\bar{a}$ from Proposition SWA.1, and so $\partial a^{*} / \partial g=0$ and $\max \left\{g-a^{*}(g), 0\right\}=g-\bar{a}$. Using (8), $d u_{\text {plan }} / d g=-\beta \delta \lambda<0$ and so $g^{*}=\bar{a}$.

Stitching the ranges together gives $g^{*}=\min \{\hat{a}, \bar{a}\}>\underline{a}$. Parts (ii) and (iii) follow, given that $\bar{a}<\hat{a} \Leftrightarrow \beta \delta \theta+\lambda<\delta \theta$. Finally, (iv) follows immediately from Proposition SWA.1 


\section{Supplementary Web Appendix III.3 Performance uncertainty}

\section{Supplementary Web Appendix III.3, Part A: Task-based goals (Section 5.3.2)}

For task-based goals, when we add uncertainty as described in the third part of Section 5.3.2 the student-actor's utility (given by (5) and (6) with no uncertainty) and the student-planner's utility (given by (7) and (8) with no uncertainty) become, respectively:

$$
\begin{gathered}
E u_{a c t}(a \mid g)=\beta \delta[\pi f(a)+(1-\pi)(0)]-[\lambda \max \{g-a, 0\}+C(a)] \\
=\beta \delta \pi \theta a-\left[\lambda \max \{g-a, 0\}+\frac{\kappa a^{2}}{2}\right] \\
E u_{\text {plan }}\left(g \mid a^{*}(g)\right)=\beta \delta^{2}\left[\pi f\left(a^{*}(g)\right)+(1-\pi)(0)\right]-\beta \delta\left[\lambda \max \left\{g-a^{*}(g), 0\right\}+C\left(a^{*}(g)\right)\right] \\
=\beta \delta^{2} \pi \theta a^{*}(g)-\beta \delta\left[\lambda \max \left\{g-a^{*}(g), 0\right\}+\frac{\kappa\left[a^{*}(g)\right]^{2}}{2}\right]
\end{gathered}
$$

Comparing (37) and (39) to (6) and (8) without uncertainty, the only difference is that every $\theta$ in the case without uncertainty has been replaced by $\pi \theta$. Since $\theta \in(0,1)$ and $\pi \theta \in(0,1)$, the results for task-based goals without uncertainty described in Supplementary Web Appendix III.2 continue to hold with uncertainty, replacing every $\theta$ with $\pi \theta$.

\section{Supplementary Web Appendix III.3, Part B: Performance-based goals (Section 5.2.2)}

For performance-based goals, when we add uncertainty as described in the third part of Section 5.2.2 the student-actor's utility (given by (1) and (2) with no uncertainty) and the studentplanner's utility (given by (3) and (4) with no uncertainty) become, respectively:

$$
\begin{aligned}
E u_{a c t}(e \mid g) & =\beta \delta\{\pi[f(e)-l \max \{g-f(e), 0\}]+(1-\pi)[0-l \max \{g-0,0\}]\}-C(e)(40) \\
& =\beta \delta\{\pi[e-l \max \{g-e, 0\}]-(1-\pi) l g\}-\frac{c e^{2}}{2} ; \\
E u_{\text {plan }}\left(g \mid e^{*}(g)\right) & = \\
\beta \delta^{2}\left\{\pi \left[f\left(e^{*}(g)\right)\right.\right. & \left.\left.-l \max \left\{g-f\left(e^{*}(g)\right), 0\right\}\right]+(1-\pi)[0-l \max \{g-0,0\}]\right\}-\beta \delta C\left(e^{*}(g)\right) \\
& =\beta \delta^{2}\left\{\pi\left[e^{*}(g)-l \max \left\{g-e^{*}(g), 0\right\}\right]-(1-\pi) l g\right\}-\beta \delta \frac{c\left[e^{*}(g)\right]^{2}}{2} .
\end{aligned}
$$

\section{Remark SWA.2}

In the absence of a goal the student exhibits time inconsistency:

(i) The student-actor chooses effort $\underline{e}=\beta \delta \pi / c$.

(ii) The student-planner would like the student-actor to exert effort $\hat{e}=\delta \pi / c>\underline{e}$. 


\section{Proof of Remark SWA.2.}

In the absence of a goal, the student-actor's utility and the student-planner's utility are given by, respectively:

$$
\begin{aligned}
E u_{a c t}(e) & =\beta \delta[\pi f(e)+(1-\pi)(0)]-C(e) \\
& =\beta \delta \pi e-\frac{c e^{2}}{2} ; \\
E u_{p l a n}(e) & =\beta \delta^{2}[\pi f(e)+(1-\pi)(0)]-\beta \delta C(e) \\
& =\beta \delta^{2} \pi e-\beta \delta \frac{c e^{2}}{2} .
\end{aligned}
$$

Both utilities are strictly concave since $c>0$. Straigthforward maximization then gives the result.

\section{Proposition SWA.3}

Let $\bar{e}=\beta \delta \pi(1+l) / c$ and recall from Remark $S W A .2$ that $\underline{e}=\beta \delta \pi / c<\bar{e}$ denotes the studentactor's effort in the absence of a goal.

(i) When $g \leq \underline{e}$, the student-actor exerts effort $e^{*}=\underline{e}$.

(ii) When $g \in[\underline{e}, \bar{e}]$, the student-actor exerts effort $e^{*}=g$.

(iii) When $g \geq \bar{e}$, the student-actor exerts effort $e^{*}=\bar{e}$.

\section{Proof of Proposition SWA.3.}

Using (41), on the range $e \in[0, g]$ :

$$
\begin{aligned}
\frac{\partial E u_{a c t}}{\partial e} & =\beta \delta \pi(1+l)-c e ; \\
\frac{\partial^{2} E u_{a c t}}{\partial e^{2}} & =-c<0 ; \text { and so } \\
e^{*} & =\min \{\bar{e}, g\} .
\end{aligned}
$$

Using (41), on the range $e \in[g, \infty)$ :

$$
\begin{aligned}
\frac{\partial E u_{a c t}}{\partial e} & =\beta \delta \pi-c e ; \\
\frac{\partial^{2} E u_{a c t}}{\partial e^{2}} & =-c<0 ; \text { and so } \\
e^{*} & =\max \{\underline{e}, g\} .
\end{aligned}
$$

(i) When $g \leq \underline{e}$, on the range $e \in[0, g], e^{*}=g$, and on the range $e \in[g, \infty), e^{*}=\underline{e}$. Thus, on the range $e \in[0, \infty), e^{*}=\underline{e}$.

(ii) When $g \in[\underline{e}, \bar{e}]$, on the range $e \in[0, g], e^{*}=g$, and on the range $e \in[g, \infty), e^{*}=g$. Thus, on the range $e \in[0, \infty), e^{*}=g$.

(iii) When $g \geq \bar{e}$, on the range $e \in[0, g], e^{*}=\bar{e}$, and on the range $e \in[g, \infty), e^{*}=g$. Thus, on the range $e \in[0, \infty), e^{*}=\bar{e}$. 


\section{Proposition SWA.4}

Recall from Remark $S W A .2$ that $\underline{e}=\beta \delta \pi / c$ denotes student-actor effort in the absence of a goal. Recall from Proposition $S W A .3$ that $\bar{e}=\beta \delta \pi(1+l) / c$ denotes maximal student-actor effort in the presence of a goal.

Let $\tilde{e}=[\delta \pi-\delta(1-\pi) l] / c$ and recall from Remark $S W A .2$ that $\hat{e}=\delta \pi / c>\tilde{e}$ denotes the studentplanner's desired effort in the absence of a goal.

There exists a $\bar{\pi} \in(0,1)$ such that for all $\pi \in[\bar{\pi}, 1)$ :

(i) The optimal choice of goal for the student-planner is given by $g^{*}=\min \{\tilde{e}, \bar{e}\}$.

(ii) When $\beta(1+l)+l(1-\pi) / \pi<1, g^{*}=\bar{e}$.

(iii) When $\beta(1+l)+l(1-\pi) / \pi \geq 1, g^{*}=\tilde{e}$.

(iv) Effort of the student-actor $e^{*}=g^{*}>\underline{e}$, and so the student-actor works harder than in the absence of goal.

\section{Proof of Proposition SWA.4.}

On the range $g \in[0, \underline{e}], e^{*}(g)=\underline{e}$ from Proposition SWA.3, and so $\partial e^{*} / \partial g=0$ and $\max \left\{g-e^{*}(g), 0\right\}=0$. Using (43), $d E u_{\text {plan }} / d g=-\beta \delta^{2}(1-\pi) l<0$ and so $g^{*}=0$. Note also that $\lim _{\pi \rightarrow 1}\left(d E u_{\text {plan }} / d g\right)=0$, and so:

$$
\lim _{\pi \rightarrow 1}\left[E u_{p l a n}(g=\underline{e})-E u_{p l a n}(g=0)\right]=0 .
$$

On the range $g \in[\underline{e}, \bar{e}], e^{*}(g)=g$ from Proposition SWA.3, and so $\partial e^{*} / \partial g=1$ and $\max \left\{g-e^{*}(g), 0\right\}=0$. Using (43), and noting that $\bar{e}>\underline{e}$ :

$$
\begin{aligned}
\frac{d E u_{\text {plan }}}{d g} & =\beta \delta^{2}[\pi-(1-\pi) l]-\beta \delta c g ; \\
\frac{d^{2} E u_{\text {plan }}}{d g^{2}} & =-\beta \delta c<0 ; \quad \text { and so } \\
g^{*} & =\min \{\max \{\tilde{e}, \underline{e}\}, \bar{e}\} .
\end{aligned}
$$

Note also that $\lim _{\pi \rightarrow 1}(\tilde{e}-\underline{e})>0$ and $\lim _{\pi \rightarrow 1}(\bar{e}-\underline{e})>0$. Thus, on the range $g \in[\underline{e}, \bar{e}]$, $g^{*}=\min \{\tilde{e}, \bar{e}\}>\underline{e}$ for $\pi$ sufficiently close to 1 .

When $\pi=1$, from the proof of Proposition 2, $g^{*}=\min \{\hat{e}, \bar{e}\}$ gives the student-planner strictly more utility than $g=\underline{e}$. Furthermore, $\lim _{\pi \rightarrow 1}(55)=(20), \lim _{\pi \rightarrow 1} \tilde{e}=\hat{e}_{\mid \pi=1}, \lim _{\pi \rightarrow 1} \bar{e}=$ $\bar{e}_{\mid \pi=1}$ and $\lim _{\pi \rightarrow 1} \underline{e}=\underline{e}_{\mid \pi=1}$. Thus:

$$
\lim _{\pi \rightarrow 1}\left[E u_{p l a n}(g=\min \{\tilde{e}, \bar{e}\})-E u_{p l a n}(g=\underline{e})\right]>0 .
$$

On the range $g \in[\bar{e}, \infty), e^{*}(g)=\bar{e}$ from Proposition SWA.3, and so $\partial e^{*} / \partial g=0$ and $\max \left\{g-e^{*}(g), 0\right\}=g-\bar{e}$. Using (43), $d E u_{\text {plan }} / d g=-\beta \delta^{2} l<0$ and so $g^{*}=\bar{e}$.

Stitching the ranges together, and using (54) and (58), there exists a $\bar{\pi} \in(0,1)$ such that $g^{*}=\min \{\tilde{e}, \bar{e}\}>\underline{e}$ for all $\pi \in[\bar{\pi}, 1)$. Parts (ii) and (iii) follow, given that $\bar{e}<\tilde{e} \Leftrightarrow \beta(1+l)+$ $l(1-\pi) / \pi<1$. Finally, (iv) follows immediately from Proposition SWA.3. 